\title{
Sensitivity analysis of magnetic field measurements for magnetic resonance electrical impedance tomography (MREIT)
}

Göksu, Cihan; Scheffler, Klaus; Ehses, Philipp; Hanson, Lars G. ; Thielscher, Axel

Published in:

Magnetic Resonance in Medicine

Link to article, DOI:

$10.1002 / \mathrm{mrm} .26727$

Publication date:

2017

Document Version

Peer reviewed version

Link back to DTU Orbit

Citation (APA):

Göksu, C., Scheffler, K., Ehses, P., Hanson, L. G., \& Thielscher, A. (2017). Sensitivity analysis of magnetic field measurements for magnetic resonance electrical impedance tomography (MREIT). Magnetic Resonance in Medicine, 79(2), 748-760. https://doi.org/10.1002/mrm.26727

\section{General rights}

Copyright and moral rights for the publications made accessible in the public portal are retained by the authors and/or other copyright owners and it is a condition of accessing publications that users recognise and abide by the legal requirements associated with these rights.

- Users may download and print one copy of any publication from the public portal for the purpose of private study or research.

- You may not further distribute the material or use it for any profit-making activity or commercial gain

- You may freely distribute the URL identifying the publication in the public portal 


\title{
Sensitivity Analysis of Magnetic Field Measurements for Magnetic Resonance Electrical Impedance Tomography (MREIT)
}

\author{
Cihan Göksu, ${ }^{1,2}$ Klaus Scheffler, ${ }^{3,4}$ Philipp Ehses, ${ }^{3,4}$ Lars G. Hanson, ${ }^{1,2 \dagger}$ and \\ Axel Thielscher ${ }^{1,2,3 \dagger *}$
}

Purpose: Clinical use of magnetic resonance electrical impedance tomography (MREIT) still requires significant sensitivity improvements. Here, the measurement of the current-induced magnetic field $\left(\Delta \mathrm{B}_{\mathrm{z}, \mathrm{c}}\right)$ is improved using systematic efficiency analyses and optimization of multi-echo spin echo (MESE) and steady-state free precession free induction decay (SSFP-FID) sequences.

Theory and Methods: Considering $T_{1}, T_{2}$, and $T_{2}^{*}$ relaxation in the signal-to-noise ratios (SNRs) of the MR magnitude images, the efficiency of MESE and SSFP-FID MREIT experiments, and its dependence on the sequence parameters, are analytically analyzed and simulated. The theoretical results are experimentally validated in a saline-filled homogenous spherical phantom with relaxation parameters similar to brain tissue. Measurement of $\Delta \mathrm{B}_{\mathrm{z}, \mathrm{c}}$ is also performed in a cylindrical phantom with saline and chicken meat.

Results: The efficiency simulations and experimental results are in good agreement. When using optimal parameters, $\Delta \mathrm{B}_{z, \mathrm{c}}$ can be reliably measured in the phantom even at injected current strengths of $1 \mathrm{~mA}$ or lower for both sequence types. The importance of using proper crusher gradient selection on the phase evolution in a MESE experiment is also demonstrated. Conclusion: The efficiencies observed with the optimized sequence parameters will likely render in-vivo human brain MREIT feasible. Magn Reson Med 000:000-000, 2017. (c) 2017 International Society for Magnetic Resonance in Medicine.

Key words: efficiency analysis; magnetic resonance electrical impedance tomography; multi-echo spin echo; steady-state free precession; sequence optimization

${ }^{1}$ Danish Research Center for Magnetic Resonance, Center for Functiona and Diagnostic Imaging and Research, Copenhagen University Hospital, Hvidovre, Denmark.

${ }^{2}$ Center for Magnetic Resonance, DTU Elektro, Technical University of Denmark, Kgs Lyngby, Denmark.

${ }^{3}$ High-Field Magnetic Resonance Center, Max-Planck-Institute for Biological Cybernetics, Tübingen, Germany.

${ }^{4}$ Department of Biomedical Magnetic Resonance, University of Tübingen, Tübingen, Germany.

Grant sponsor: Lundbeck Foundation; Grant numbers: R118-A11308; R59 A5399 (PI Hartwig Siebner).

*Correspondence to: Axel Thielscher, Danish Research Center for Magnetic Resonance, Center for Functional and Diagnostic Imaging and Research, Copenhagen University Hospital Hvidovre, Section 714, Kettegaard Allé 30, 2650 Hvidovre, Denmark. E-mail: axelt@drcmr.dk

†These authors contributed equally to this work.

Received 30 November 2016; revised 2 March 2017; accepted 29 March 2017

DOI 10.1002/mrm.26727

Published online 00 Month 2017 in Wiley Online Library (wileyonlinelibrary. com).

(C) 2017 International Society for Magnetic Resonance in Medicine

\section{INTRODUCTION}

Magnetic resonance current density imaging (MRCDI) and magnetic resonance electrical impedance tomography (MREIT) are two emerging imaging modalities, which combine MRI with externally applied currents (either direct current or alternating current at low frequencies combined with repeated refocusing pulses (1)) to reconstruct the current density distribution and ohmic conductivity variation inside body tissue (2-7). This may open up novel ways to characterize pathological tissue (8). In addition, better knowledge of the conductivity distribution would allow improving the accuracy of source localization methods for electroencephalography and magnetoencephalography (9) and enable better spatial targeting of neurostimulation methods $(10,11)$. However, MRCDI and MREIT are still hampered by their low sensitivity, which prevents their clinical usage.

In both modalities, electrical current is applied in synchrony with the MRI pulse sequence. The current flow induces a magnetic field distribution in the body, and the component of the induced magnetic field $\left(\Delta \mathrm{B}_{\mathrm{z}, \mathrm{c}}\right)$ which is parallel to the main magnetic field $\left(\mathrm{B}_{0}\right)$ creates a phase perturbation in the MRI signal that can be measured (5). The sensitivity of the $\Delta \mathrm{B}_{\mathrm{z}, \mathrm{c}}$ measurement directly affects the accuracy and quality of the reconstructed current and conductivity distributions (12). However, a reliable $\Delta \mathrm{B}_{\mathrm{z}, \mathrm{C}}$ measurement in in-vivo situations is crucial and challenging as only weak currents can be applied to the human body in the low frequency range, e.g. around 1-2 mA for brain studies (13). Optimized MR sequences which allow for efficient $\Delta \mathrm{B}_{\mathrm{z}, \mathrm{c}}$ measurements within clinically relevant scan times are thus important to enable in-vivo applications of MRCDI and MREIT.

Up to now, single-echo spin echo (SE), multi-echo spin echo (MESE), gradient recalled echo, echo planar imaging, and steady-state free precession free induction decay (SSFP-FID) MREIT experiments have been performed $(5,14-19)$. Sequences with refocusing pulses are more robust to main field inhomogeneities and have a higher signal-to-noise ratio (SNR), but imaging time is prolonged. On the other hand, the gradient-echo sequences are more vulnerable to main field inhomogeneities and have less SNR attributed to $\mathrm{T}_{2}^{*}$ decay, but are generally faster.

In this study, systematic efficiency analyses of two sensitive sequences (MESE and SSFP-FID) are performed, thereby considering the impact of $\mathrm{T}_{1}, \mathrm{~T}_{2}$, and $\mathrm{T}_{2}^{*}$ relaxation and radiofrequency (RF) imperfections on 

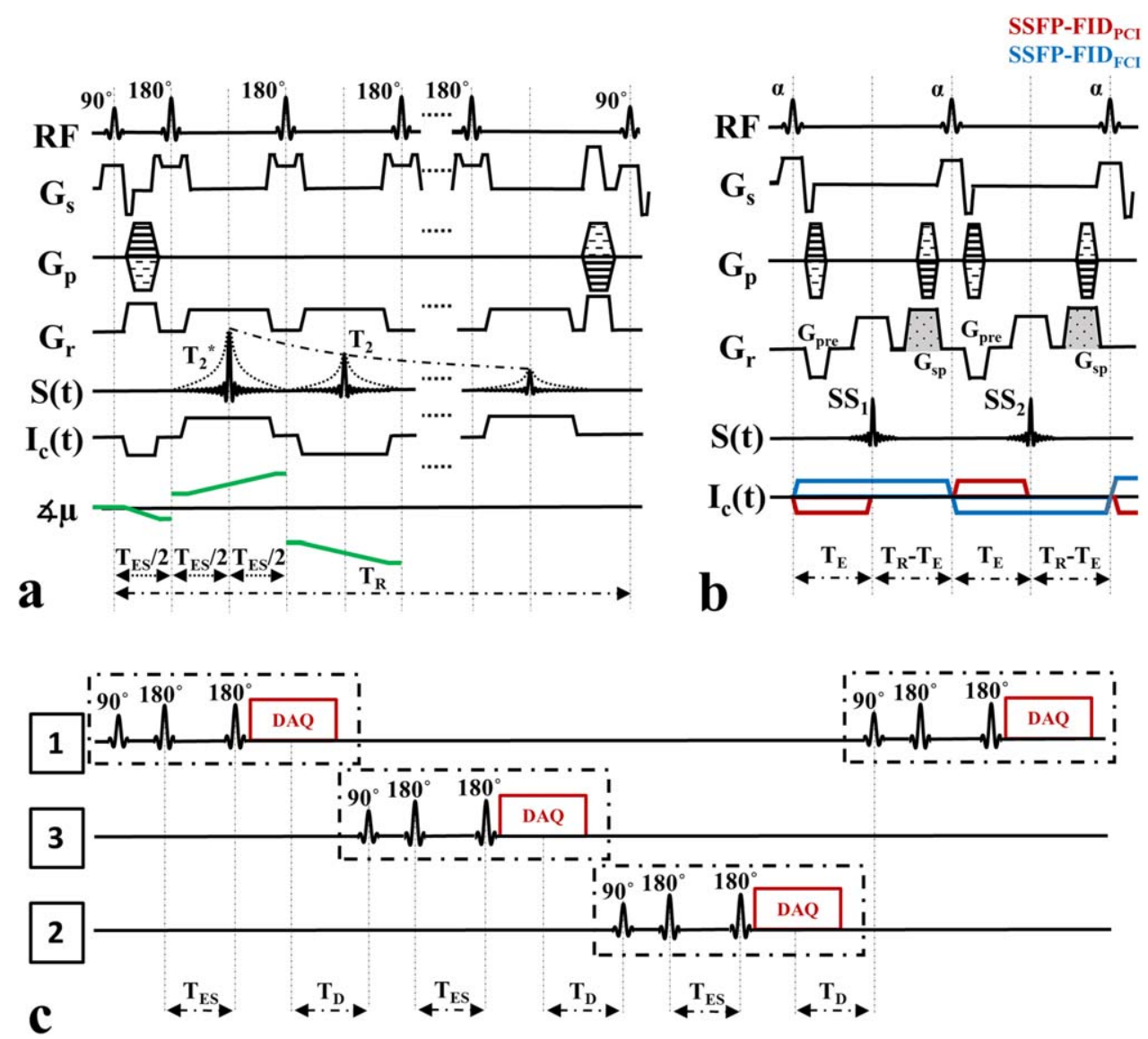

FIG. 1. (a) Diagram of the MESE MREIT pulse sequence with equal and symmetric echo spacing. The sequence is composed of a $90^{\circ}$ excitation pulse preceding repetitive $180^{\circ}$ refocusing pulses, so that multiple echoes are created. Crusher gradients are used to preserve the desired echo pathways, while eliminating unwanted ones caused by nonideal refocusing pulses (27). At the end of the sequence, phase encoding rewinder and spoiler gradients are used to eliminate unwanted effects of remaining transverse magnetization. This is followed by a dead time $T_{D}$ after which the slice (or the next slice for multi-slice measurements; see subfigure c) is excited again. The injected bipolar electrical current is synchronized with the RF pulses, so that the phase of the continuous complex transverse magnetization $(x \mu)$ increases linearly over time. (b) Sequence diagrams of the two SSFP-FID variants. An SSFP sequence is composed of repetitive constant tip angle and in-phase excitation pulses, where the interval $T_{R}$ between each RF pulse is constant. These conditions are enough to reach a steady state (30). In case of a bipolar electrical current injection in synchrony with the SSFP-FID sequence, the continuous transverse magnetization phase evolves in opposite directions in odd and even $\mathrm{T}_{\mathrm{R}}$ periods, which induces two different steady-state conditions with opposite current-induced phases. Please note that unlike in the original study of Lee et al (19), we decided to inject electrical current until $T_{E}$ for SSFP-FID ${ }_{P C I}$ in order to test its most efficient case. On the other hand, the current is injected within the entire $\mathrm{T}_{\mathrm{R}}$ period in SSFP-FID $\mathrm{FCl}_{\text {. }}$ (c) Interleaved multi-slice acquisition of MESE.

SNR. All results are experimentally validated in a salinefilled homogenous spherical phantom with relaxation parameters similar to brain tissue. For MESE (Fig. 1a,c), it is simulated how efficiency depends on the relevant sequence parameters, which are shown to be the echo spacing $\mathrm{T}_{\mathrm{ES}}$, the number of echoes $\mathrm{N}_{\text {echo }}$, and the dead time $\mathrm{T}_{\mathrm{D}}$. The efficiency change for multi-slice acquisition is subsequently assessed. In addition, the importance of selecting the proper echo pathways on the phase evolution is demonstrated. Furthermore, two different SSFPFID variants (Fig. 1b) are simulated and compared. The more efficient variant is subsequently optimized with respect to the utilized tip angle $\alpha$, echo time $\mathrm{T}_{\mathrm{E}}$, and repetition time $\mathrm{T}_{\mathrm{R}}$. In final experiments, the efficiencies of the optimized MESE and SSFP-FID sequences are directly compared, and $\Delta \mathrm{B}_{\mathrm{z}, \mathrm{c}}$ measurements are performed for both MESE and SSFP-FID for a nonhomogeneous phantom.

\section{THEORY}

\section{Efficiency of an MREIT Experiment}

We use the following notation of efficiency $\eta_{\text {seq }}$ to characterize the performance of a sequence (20), thereby relating the SNR of the acquired $\Delta \mathrm{B}_{\mathrm{z}, \mathrm{c}}$ image to the required total scan time $\mathrm{T}_{\text {tot }}$ (Eq. 1):

$$
\eta_{\text {seq }}=\frac{\mathrm{SNR}_{\Delta \mathrm{B}_{\mathrm{z}, \mathrm{c}}}}{\sqrt{\mathrm{T}_{\mathrm{tot}}}}=\frac{\left|\Delta \mathrm{B}_{\mathrm{z,c}}\right|}{\sigma_{\Delta \mathrm{B}_{\mathrm{z}, \mathrm{c}}} \sqrt{\mathrm{T}_{\mathrm{tot}}}}
$$

$\left|\Delta \mathrm{B}_{\mathrm{z}, \mathrm{c}}\right|$ is the magnitude of the current-induced magnetic field and $\sigma_{\Delta \mathrm{Bz}, \mathrm{c}}$ the noise standard deviation of $\Delta \mathrm{B}_{\mathrm{z}, \mathrm{c}}$. Please note that $\eta_{\text {seq }}$ varies spatially, because $\Delta \mathrm{B}_{\mathrm{z}, \mathrm{C}}$ depends on the injected current strength, electrode placement, electrode geometry, and conductivity distribution. In addition, $\sigma_{\Delta \mathrm{Bz}, \mathrm{c}}$ depends on the SNR of the MR image and the phase sensitivity of MRI sequence. In the following, we derive how the 
efficiency depends on sequence and tissue relaxation parameters. The resulting equations are then used to determine the optimal parameter settings by numerical simulations.

\section{MESE MREIT}

The pulse sequence of a standard MESE MREIT sequence with equal and symmetric echo spacing is shown in Figure 1a,c. For current injection within periods free of RF pulses, the measured $\Delta \mathrm{B}_{\mathrm{z}, \mathrm{C}}$ from each single echo and its noise variance were reported previously $(17,21,22)$ and are given by Equations [2] and [3]:

$$
\begin{aligned}
\Delta \mathrm{B}_{\mathrm{z}, \mathrm{C}}^{\mathrm{n}} & =\frac{\angle \mathrm{M}_{\mathrm{n}}{ }^{+}-\angle \mathrm{M}_{\mathrm{n}}{ }^{-}}{2 \gamma\left[\left(\mathrm{T}_{\mathrm{ES}}-\tau_{\pi}\right) \mathrm{n}-0.5 \tau_{\pi / 2}\right]} \\
\operatorname{Var}\left\{\Delta \mathrm{B}_{\mathrm{z}, \mathrm{C}}^{\mathrm{n}}\right\} & =\frac{1}{4 \gamma^{2} \mathrm{SNR}_{\mathrm{n}}^{2}\left[\left(\mathrm{~T}_{\mathrm{ES}}-\tau_{\pi}\right) \mathrm{n}-0.5 \tau_{\pi / 2}\right]^{2}}
\end{aligned}
$$

$\angle \mathrm{M}_{\mathrm{n}}{ }^{+}$and $\angle \mathrm{M}_{\mathrm{n}}{ }^{-}$are the phase of the complex $\mathrm{MR}$ images from the $n$th echo with positive $(+)$ and negative $(-)$ constant current injection, $\mathrm{SNR}_{\mathrm{n}}$ is the SNR of the magnitude image from the nth echo, and $\gamma$ denotes the gyromagnetic ratio. $\tau_{\pi}$ and $\tau_{\pi / 2}$ are the durations of the $180^{\circ}$ and $90^{\circ} \mathrm{RF}$ pulses where current is not applied.

The $\Delta \mathrm{B}_{\mathrm{z}, \mathrm{c}}$ measurements can be optimally combined across echoes by weighting each by the inverse of its variance. Normalizing by a common factor to ensure that the weights across all echoes sum to 1, and adding the weighted images, the noise variance of the combined $\Delta \mathrm{B}_{\mathrm{z}, \mathrm{C}}$ is then given by Equation [4] (17):

$$
\operatorname{Var}\left\{\Delta \mathrm{B}_{\mathrm{z}, \mathrm{C}}^{\mathrm{comb}}\right\}=\frac{1}{\sum_{\mathrm{n}=1}^{\mathrm{N}_{\text {echo }}} 4 \gamma^{2} \mathrm{SNR}_{\mathrm{n}}^{2}\left[\left(\mathrm{~T}_{\mathrm{ES}}-\tau_{\pi}\right) \mathrm{n}-0.5 \tau_{\pi / 2}\right]^{2}}
$$

Applying Equation [4] to Equation [1] finally gives the efficiency of measuring the combined $\Delta \mathrm{B}_{\mathrm{z}, \mathrm{c}}$ (Eq. [5]):

$$
\eta_{\mathrm{MESE}}=\frac{\left|\Delta \mathrm{B}_{\mathrm{z, \textrm {c }}}^{\mathrm{comb}}\right|}{\sqrt{\mathrm{T}_{\text {tot }}}} \sqrt{\sum_{\mathrm{n}=1}^{\mathrm{N}_{\text {echo }}} 4 \gamma^{2} \mathrm{SNR}_{\mathrm{n}}^{2}\left[\left(\mathrm{~T}_{\mathrm{ES}}-\tau_{\pi}\right) \mathrm{n}-0.5 \tau_{\pi / 2}\right]^{2}}
$$

In order to further relate the efficiency stated in Equation [5] to the sequence and tissue relaxation parameters, the $1 \mathrm{D}$ case is considered. The continuous complex transverse magnetization $\mu(\mathrm{x}, \mathrm{t})$ depends on $\mathrm{T}_{1}, \mathrm{~T}_{2}, \mathrm{~T}_{2}^{*}$ relaxations and a signal loss factor caused by imperfect refocusing. Defining $\beta_{\mathrm{RF}}$ to be the fraction of preserved signal after each refocusing pulse, and under an assumption of a Lorentzian spectral density distribution (Eq. [6]),

$$
\begin{aligned}
\mu^{\mathrm{n}}(\mathrm{x}, \mathrm{t})= & \mu_{0}(\mathrm{x})\left[1-\mathrm{e}^{-\mathrm{T}_{\text {rec }} / \mathrm{T}_{1}(\mathrm{x})}\right] \mathrm{e}^{-\mathrm{nT} \mathrm{TS}_{\mathrm{ES}} / \mathrm{T}_{2}(\mathrm{x})} \mathrm{e}^{-\mid \mathrm{t}-\mathrm{nT} \mathrm{T}_{\mathrm{ES}} / / \mathrm{T}_{2}^{*}(\mathrm{x})} \beta_{\mathrm{RF}}^{\mathrm{n}} \\
& \text { for }(\mathrm{n}-0.5) \mathrm{T}_{\mathrm{ES}}<\mathrm{t}<(\mathrm{n}+0.5) \mathrm{T}_{\mathrm{ES}}
\end{aligned}
$$

$\mu_{0}(\mathrm{x})$ is the equilibrium magnetization distribution and $\mathrm{T}_{\text {rec }}$ is the $\mathrm{T}_{1}$ recovery period between nulling of longitudinal magnetization after the last refocusing pulse and re-excitation of the same slice (the factor $\beta_{\mathrm{RF}}^{\mathrm{n}}$ expresses the accumulated effect of imperfect refocusing pulses in later echoes). The acquired signal $S\left(k_{x}, t\right)$ for the nth MESE echo can then be expressed as Equation [7]:

$$
S^{n}\left(k_{x}, t\right)=\int_{\text {object }} \mu^{n}(x, t) e^{-j 2 \pi k_{x} x} d x
$$

The object can conceptually be considered a distribution of point sources. Combining Equations [6] and [7] and assuming an idealized single point distribution $\left(\mu_{0}(x)=\delta(x)\right)$, constant relaxation times, $\beta_{R F}$, and noise $\sigma$, and a standard k-space trajectory $\mathrm{k}_{\mathrm{x}}(\mathrm{t})=\frac{\gamma \mathrm{G}_{\mathrm{x}}}{2 \pi}$ $\left(\mathrm{t}-\mathrm{nT}_{\mathrm{ES}}\right)$ results in the conclusion that the $\mathrm{SNR}_{\mathrm{n}}$ in Equation [5] is proportional to attenuation factors $\left(\alpha_{\mathrm{T}_{1}}, \alpha_{\mathrm{T}_{2}}, \alpha_{\mathrm{T}_{2}^{*}}\right.$ and $\left.\alpha_{\mathrm{RF}}\right)$ caused by the $\mathrm{T}_{1}, \mathrm{~T}_{2}, \mathrm{~T}_{2}^{*}$ relaxations and RF imperfections, which can be expressed as Equation [8]:

$$
\begin{aligned}
& \mathrm{SNR}_{\mathrm{n}}=\frac{\left|\mathrm{M}_{n}\right|}{\sigma} \propto \alpha_{\mathrm{T}_{1}} \alpha_{\mathrm{T}_{2}} \alpha_{\mathrm{T}_{2}^{*}} \alpha_{\mathrm{RF}} \\
& \alpha_{\mathrm{T}_{1}}=1-\mathrm{e}^{-\mathrm{T}_{\mathrm{rec}} / \mathrm{T}_{1}}, \quad \alpha_{\mathrm{T}_{2}}=\mathrm{e}^{-\mathrm{nT}_{\mathrm{ES}} / \mathrm{T}_{2}}, \quad \alpha_{\mathrm{RF}}=\beta_{R F}^{n} \\
& \alpha_{\mathrm{T}_{2}}=\frac{1}{N_{\mathrm{x}} \Delta k_{\mathrm{X}}} \int_{-\mathrm{N}_{\mathrm{x}} \Delta \mathrm{k}_{\mathrm{x}} / 2}^{\mathrm{N}_{\mathrm{x}} \Delta \mathrm{k}_{\mathrm{x}} / 2} \mathrm{e}^{-2 \pi \mid \mathrm{k}_{\mathrm{x}} / / \gamma \mathrm{G}_{\mathrm{x}} \mathrm{T}_{2}^{*}} \mathrm{dk}_{\mathrm{x}}=\frac{2 \mathrm{~T}_{2}^{*}\left(1-\mathrm{e}^{-\mathrm{T}_{\mathrm{s}} / 2 \mathrm{~T}_{2}^{*}}\right)}{\mathrm{T}_{\mathrm{s}}}
\end{aligned}
$$

$\left|M_{n}\right|$ is the noise-free reconstructed MR magnitude image, which is proportional to $\mu^{\mathrm{n}}$ given in Equation [6]. $G_{x}$ is the readout gradient strength, $N_{x}$ the readout matrix size, $\mathrm{T}_{\mathrm{s}}$ the readout period, and $\Delta \mathrm{k}_{\mathrm{x}}$ the spatial frequency resolution. The recovery of the longitudinal magnetization is almost linear for $\mathrm{T}_{\mathrm{ES}}<<\mathrm{T}_{1}$ within the period between refocusing pulses. Therefore, it can be assumed that the longitudinal magnetization is nulled at each echo, and $\mathrm{T}_{\text {rec }}$ can be approximated as shown by Equation [9]:

$$
\mathrm{T}_{\text {rec }} \approx\left(\mathrm{N}_{\text {slice }}-1\right) \mathrm{N}_{\text {echo }} \mathrm{T}_{\mathrm{ES}}+\mathrm{N}_{\text {slice }} \mathrm{T}_{\mathrm{D}}
$$

$\mathrm{N}_{\text {slice }}$ and $\mathrm{T}_{\mathrm{D}}$ are number of slices and dead time, respectively. In combination, Equations [5], [8], and [9] characterize the dependency of the efficiency of a MESE MREIT experiment on the sequence and tissue parameters.

\section{SSFP-FID MREIT}

Lee et al have previously studied different SSFP variants for MREIT (19). Here, we investigate their most sensitive variant further, in which the current is applied before the readout period (SSFP-FID $_{\text {PCI }}$ with partial current injection; Fig. 1b). In addition, we propose a novel variant in which the current is injected within the entire $\mathrm{T}_{\mathrm{R}}$ period (SSFP-FID FCI $_{\text {with full cur- }}$ rent injection; Fig. 1b). The analytical solutions for the steady-state magnetization immediately after excitation with bipolar current injection have been derived by Lee et al (19) (Eq. [10]): 


$$
\begin{aligned}
& \mu_{{s s_{1}}_{1}}\left(\mathrm{t}=0^{+}\right)=\frac{\mu_{0}\left(1-\mathrm{E}_{1}\right) \sin (\alpha)}{\mathrm{D}}\left(\begin{array}{c}
\mathrm{A}_{1} \mathrm{e}^{-2 \mathrm{j}\left(\varphi_{\mathrm{g}}+\varphi_{\mathrm{b}}\right)}+\mathrm{A}_{2} \mathrm{e}^{-2 \mathrm{j} \varphi_{\mathrm{c}}}+\mathrm{A}_{3} \mathrm{e}^{\mathrm{j}\left(\varphi_{\mathrm{g}}+\varphi_{\mathrm{b}}-\varphi_{\mathrm{c}}\right)} \\
+\mathrm{A}_{4} \mathrm{e}^{-\mathrm{j}\left(\varphi_{\mathrm{g}}+\varphi_{\mathrm{b}}-\varphi_{\mathrm{c}}\right)}+\mathrm{A}_{5} \mathrm{e}^{-\mathrm{j}\left(\varphi_{\mathrm{g}}+\varphi_{\mathrm{b}}+\varphi_{\mathrm{c}}\right)}+\mathrm{A}_{6}
\end{array}\right) \\
& \mu_{\mathrm{ss}_{2}}\left(\mathrm{t}=0^{+}\right)=\frac{\mu_{0}\left(1-\mathrm{E}_{1}\right) \sin (\alpha)}{\mathrm{D}}\left(\begin{array}{c}
\mathrm{A}_{1} \mathrm{e}^{-2 \mathrm{j}\left(\varphi_{\mathrm{g}}+\varphi_{\mathrm{b}}\right)}+\mathrm{A}_{2} \mathrm{e}^{2 \mathrm{j} \varphi_{\mathrm{c}}}+\mathrm{A}_{3} \mathrm{e}^{\mathrm{j}\left(\varphi_{\mathrm{g}}+\varphi_{\mathrm{b}}+\varphi_{\mathrm{c}}\right)} \\
+\mathrm{A}_{4} \mathrm{e}^{-\mathrm{j}\left(\varphi_{\mathrm{g}}+\varphi_{\mathrm{b}}+\varphi_{\mathrm{c}}\right)}+\mathrm{A}_{5} \mathrm{e}^{-\mathrm{j}\left(\varphi_{\mathrm{g}}+\varphi_{\mathrm{b}}-\varphi_{\mathrm{c}}\right)}+\mathrm{A}_{6}
\end{array}\right)
\end{aligned}
$$

with

$$
\begin{aligned}
& \mathrm{A}_{1}=\mathrm{E}_{2}^{2}\left(1+\mathrm{E}_{1}\right)(1+\cos (\alpha)), \mathrm{A}_{2}=\mathrm{E}_{2}^{2}\left(1-\mathrm{E}_{1}\right)(1-\cos (\alpha)) \\
& \mathrm{A}_{3}=-\mathrm{E}_{2}\left(1+\mathrm{E}_{1}\right)(1+\cos (\alpha)), \mathrm{A}_{4}=\mathrm{E}_{2}\left(1-\mathrm{E}_{1}\right)(1-\cos (\alpha)) \\
& \mathrm{A}_{5}=2 \mathrm{E}_{2}^{3}\left(\mathrm{E}_{1}+\cos (\alpha)\right), \mathrm{A}_{6}=-2\left(1+\mathrm{E}_{1} \cos (\alpha)\right) \\
& \mathrm{D}=\mathrm{E}_{2}{ }^{2}\left(1-\mathrm{E}_{1}^{2}\right)\left[(\cos (\alpha)+1)^{2} \cos \left(2\left(\varphi_{\mathrm{g}}+\varphi_{\mathrm{b}}\right)\right)+(\cos (\alpha)-1)^{2} \cos \left(2 \varphi_{\mathrm{C}}\right)\right]+ \\
& 2 \mathrm{E}_{1} \mathrm{E}_{2}\left(1-\mathrm{E}_{2}^{2}\right)(\cos (2 \alpha)-1) \cos \left(\varphi_{\mathrm{g}}+\varphi_{\mathrm{b}}\right) \cos \left(\varphi_{\mathrm{C}}\right)+ \\
& 2\left(\mathrm{E}_{1} \cos (\alpha)+1\right)\left(\mathrm{E}_{1} \cos (\alpha)-1\right)+2 \mathrm{E}_{2}^{4}\left(\mathrm{E}_{1}+\cos (\alpha)\right)\left(\mathrm{E}_{1}-\cos (\alpha)\right) \\
& \text { and } \\
& \mathrm{E}_{1}=\mathrm{e}^{-\mathrm{T}_{\mathrm{R}} / \mathrm{T}_{1}}, \mathrm{E}_{2}=\mathrm{e}^{-\mathrm{T}_{\mathrm{R}} / \mathrm{T}_{2}}
\end{aligned}
$$

Here, $\mu_{\mathrm{ss} 1}$ and $\mu_{\mathrm{ss} 2}$ are the alternating first and second steady-state transversal magnetizations; $\mu_{0}$ is the thermal equilibrium magnetization, $\alpha$ the tip angle, $\varphi_{\mathrm{g}}$ the gradient-induced phase, $\varphi_{\mathrm{b}}$ the $\mathrm{B}_{0}$ inhomogeneityinduced phase, and $\varphi_{\mathrm{C}}$ the current-induced phase. The steady-state magnetization at $\mathrm{T}_{\mathrm{E}}$ becomes (Eq. [11]):

$\mu_{S_{1}}^{\mathrm{FID}_{1}}\left(\Delta \mathrm{B}_{\mathrm{z}, \mathrm{C}}, \mathrm{t}=\mathrm{T}_{\mathrm{E}}\right)=\mu_{\mathrm{Ss}_{1}}\left(\varphi_{\mathrm{C}}=\gamma \Delta \mathrm{B}_{\mathrm{z,C}} \mathrm{T}_{\mathrm{c}}, \mathrm{t}=0^{+}\right) \mathrm{e}^{-\mathrm{T}_{\mathrm{E}} / \mathrm{T}_{2}} \mathrm{e}^{\mathrm{j} \gamma\left(\Delta \mathrm{B}_{0}+\Delta \mathrm{B}_{\mathrm{z}, \mathrm{c}}\right) \mathrm{T}_{\mathrm{E}}}$

$\mu_{S^{2} S_{2}}^{\mathrm{FI}_{1}}\left(\Delta \mathrm{B}_{\mathrm{z}, \mathrm{C}}, \mathrm{t}=\mathrm{T}_{\mathrm{E}}\right)=\mu_{\mathrm{Ss}_{2}}\left(\varphi_{\mathrm{C}}=\gamma \Delta \mathrm{B}_{\mathrm{z}, \mathrm{C}} \mathrm{T}_{\mathrm{C}}, \mathrm{t}=0^{+}\right) \mathrm{e}^{-\mathrm{T}_{\mathrm{E}} / \mathrm{T}_{2}} \mathrm{e}^{\mathrm{j} \gamma\left(\Delta \mathrm{B}_{0}-\Delta \mathrm{B}_{\mathrm{z}, \mathrm{c}}\right) \mathrm{T}_{\mathrm{E}}}$

$\mu_{S_{1}}^{\mathrm{FID}_{2}}\left(\Delta \mathrm{B}_{\mathrm{z}, \mathrm{c}}, \mathrm{t}=\mathrm{T}_{\mathrm{E}}\right)=\mu_{\mathrm{Ss}_{1}}\left(\varphi_{\mathrm{C}}=\gamma \Delta \mathrm{B}_{\mathrm{z}, \mathrm{C}} \mathrm{T}_{\mathrm{R}}, \mathrm{t}=0^{+}\right) \mathrm{e}^{-\mathrm{T}_{\mathrm{E}} / \mathrm{T}_{2}} \mathrm{e}^{\mathrm{j} \gamma\left(\Delta \mathrm{B}_{0}+\Delta \mathrm{B}_{\mathrm{z}, \mathrm{c}}\right) \mathrm{T}_{\mathrm{E}}}$

$\mu_{\mathrm{SS}_{2}}^{\mathrm{FID}_{2}}\left(\Delta \mathrm{B}_{\mathrm{z}, \mathrm{C}}, \mathrm{t}=\mathrm{T}_{\mathrm{E}}\right)=\mu_{\mathrm{ss}_{2}}\left(\varphi_{\mathrm{C}}=\gamma \Delta \mathrm{B}_{\mathrm{z}, \mathrm{C}} \mathrm{T}_{\mathrm{R}}, \mathrm{t}=0^{+}\right) \mathrm{e}^{-\mathrm{T}_{\mathrm{E}} / \mathrm{T}_{2}} \mathrm{e}^{\mathrm{j} \gamma\left(\Delta \mathrm{B}_{0}-\Delta \mathrm{B}_{\mathrm{z}, \mathrm{c}}\right) \mathrm{T}_{\mathrm{E}}}$

[11]

where $\mathrm{T}_{\mathrm{C}}$ is the injected current pulse width and $\Delta \mathrm{B}_{0}$ the local $\mathrm{B}_{0}$ inhomogeneity. Assuming sufficiently strong spoiler gradients creating a uniform intravoxel phase distribution at the end of each repetition, the SSFP-FID signal is equal to the integral of the steady-state magnetization with respect to $\varphi_{\mathrm{g}}$ over a $2 \pi$ interval $(19,23)$. Therefore, constant phase shifts attributed to RF phase imperfections or local $B_{0}$ inhomogeneity do not influence the steady-state signal.

In contrast to MESE, SSFP-FID has a nonlinear dependence of $\Delta \mathrm{B}_{\mathrm{z}, \mathrm{c}}$ on the phase of the transverse magnetization. However, for weak currents, this can be well approximated by a linear relationship (Eq. [12]):

$$
\Delta \mathrm{B}_{\mathrm{z}, \mathrm{C}}=\frac{\angle \mathrm{M}_{\mathrm{SS} 1}-\angle \mathrm{M}_{\mathrm{SS} 2}}{\mathrm{~m}_{\mathrm{seq}}}
$$

where $\angle \mathrm{M}_{\mathrm{SS} 1}$ and $\angle \mathrm{M}_{\mathrm{SS} 2}$ are the phases of the first and second steady-state complex $\mathrm{MR}$ images and $\mathrm{m}_{\mathrm{seq}}=\partial\left(\angle \mathrm{M}_{\mathrm{SS} 1}-\angle \mathrm{M}_{\mathrm{SS} 2}\right) / \partial \Delta \mathrm{B}_{\mathrm{z}, \mathrm{c}}$ express the field dependence on the phase change. The standard deviation of the $\Delta \mathrm{B}_{\mathrm{z}, \mathrm{c}}$ estimate and the efficiency can then be calculated as Equation [13]:

$$
\begin{aligned}
& \sigma_{\Delta B_{z, c}}=\frac{1}{m_{\text {seq }} S N R}, \\
& \eta_{\text {SSFP-FID }}=\frac{\left|\angle \mathrm{M}_{\mathrm{SS} 1}-\angle \mathrm{M}_{\mathrm{SS} 2}\right|}{\sqrt{\mathrm{T}_{\mathrm{tot}}}} \mathrm{SNR}
\end{aligned}
$$

with SNR being the SNR of the magnitude image.

\section{METHODS}

In this section, the numerical simulation methods are introduced, which were used to systematically evaluate the efficiencies of MESE and SSFP-FID MREIT based on the above theory. This is followed by a description of the experimental methods used to validate the theory and simulations.

\section{Simulations}

The efficiency of MESE was simulated based on Equations [5], [8], and [9]. Relaxation times of $\mathrm{T}_{1}=1.1$ seconds, $\mathrm{T}_{2}=100 \mathrm{~ms}$, and $\mathrm{T}_{2}^{*}=50 \mathrm{~ms}$ were used, similar to those of brain tissue (24). The RF pulse durations and their efficiency were set to $\tau_{\pi / 2}=2.048 \mathrm{~ms}, \tau_{\pi}=2.56 \mathrm{~ms}$, and $\beta_{\mathrm{RF}}=0.86$ to match those of the clinical $3 \mathrm{~T}$ scanner used in the MESE experiments (the MESE section also describes the measurement of $\beta_{\mathrm{RF}}$ ). The longest crusher gradient duration was set to $\mathrm{T}_{\text {crush }}=7.5 \mathrm{~ms}$, and this value was determining the minimal echo spacing in the simulations. Because the SNR of an MR image scales with the square root of data acquisition time (21), the lowest possible sampling bandwidths (BWs) were chosen in all simulations. 
$\mathbf{a}$
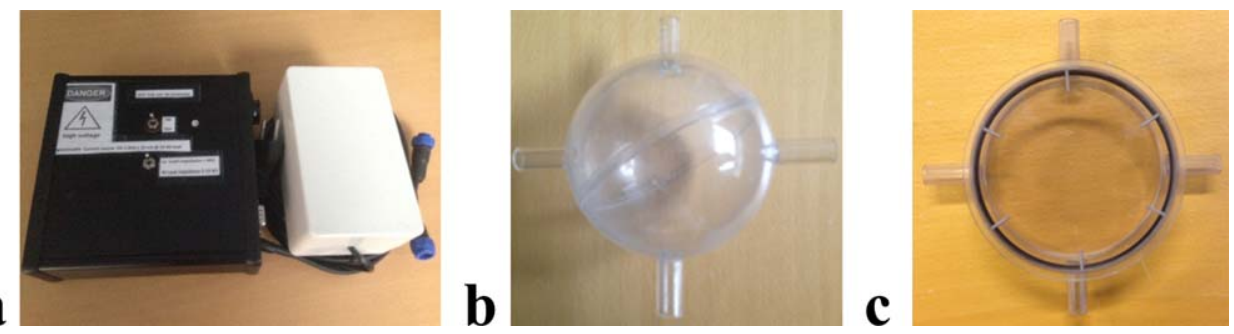

FIG. 2. (a) Photograph of the current source. (b) Phantom 1 was spherical with a diameter of $10 \mathrm{~cm}$, filled with saline $(1.45 \mathrm{~g} / \mathrm{L}$ of $\mathrm{NaCl})$ and doped with $0.1 \mathrm{mM}$ of $\mathrm{MnCl}_{2}$ to reach relaxation times of $T_{1}=1.1 \mathrm{~s}$ and $T_{2}=100 \mathrm{~ms}(31) . T_{1}$ values were determined by repeating an inversion recovery gradient recalled echo (IR-GRE) sequence for different inversion times. $T_{2}$ values were measured by repeating a spin echo sequence for a range of echo times. Also, the tip angle variation over the imaging region was investigated using a doubleangle method (32). The tip angle map was created by repeating an RF spoiled fast low angle shot sequence with two different tip angles ( $\alpha=30^{\circ}$ and $\alpha=60^{\circ} ; \mathrm{T}_{\mathrm{E}}=5 \mathrm{~ms} ; \mathrm{T}_{\mathrm{R}}=5$ seconds). The tip angle deviation over the imaging region was around $10 \%$. (c) Phantom 2 was cylindrical with $10 \mathrm{~cm}$ in diameter and $3 \mathrm{~cm}$ in height, filled with the same saline solution and with a piece of organic chicken meat placed in its center. The relaxation parameters in Phantom 2 were around $T_{1}=1.05$ seconds, $T_{2}=110$ ms in the saline region, and $\mathrm{T}_{1}=1.1$ seconds, $\mathrm{T}_{2}=50 \mathrm{~ms}$ in the chicken meat.

- For a single-slice acquisition, the SNR and efficiency of $\Delta \mathrm{B}_{\mathrm{z}, \mathrm{C}}$ were simulated for a fixed dead time $\mathrm{T}_{\mathrm{D}}=510 \mathrm{~ms}$ to demonstrate the effects of $\mathrm{N}_{\text {echo }}$ and $\mathrm{T}_{\mathrm{ES}}$. The simulations were performed for $\mathrm{T}_{\mathrm{ES}}=[20-$ $160]$ ms and $\mathrm{N}_{\text {echo }}=[1-8]$.

- For multi-slice acquisitions, the dependence of the efficiency on $T_{D}$ was obtained for different numbers of slices $\mathrm{N}_{\text {slice }}=[1-5,15]$, whereas the $\mathrm{T}_{\mathrm{ES}}$ and $\mathrm{N}_{\text {echo }}$ giving the highest efficiency were selected for each $\mathrm{T}_{\mathrm{D}}$. The simulations were performed for $\mathrm{T}_{\mathrm{D}}=[0.1-10] \mathrm{s}$, $\mathrm{T}_{\mathrm{ES}}=[20-200] \mathrm{ms}$, and $\mathrm{N}_{\text {echo }}=[1-8]$ (even for $\mathrm{T}_{\mathrm{ES}}=200 \mathrm{~ms}$, the assumption of a linear recovery of the longitudinal magnetization causes an error of less than $9 \%$ when reading out the optimal $\mathrm{T}_{\mathrm{D}}$ ).

The SSFP-FID simulations were performed by using $3 \mathrm{D}$ rotation and relaxation matrices (25) and were crosschecked by the analytically derived Equations [10] to [13]. The number of isochromates in the simulations was 100, instantaneous RF pulses were assumed, and the spoiler gradients were modeled as creating $4 \pi$ intravoxel phase dispersion. Relaxation times of $\mathrm{T}_{1}=1.1 \mathrm{~s}, \mathrm{~T}_{2}=100$ $\mathrm{ms}$, and $\mathrm{T}_{2}^{*}=50 \mathrm{~ms}$ were used.

- First, the dependence of the steady-state transverse magnetization magnitude and phase on $\Delta \mathrm{B}_{\mathrm{z,c}}$ were simulated for both SSFP-FID variants and compared with spin echo. The simulation parameters were $\alpha=60^{\circ}, \mathrm{TR}=20 \mathrm{~ms}, \mathrm{TE}=10 \mathrm{~ms}$, and a range of $\Delta \mathrm{B}_{\mathrm{z}, \mathrm{C}}=[-100$ to 100$] \mathrm{nT}$ was covered.

- For the more efficient variant SSFP-FID ${ }_{\text {FCI }}$ SNR and efficiency of $\Delta \mathrm{B}_{\mathrm{z}, \mathrm{c}}$ measurements were simulated in order to demonstrate the effect of $\mathrm{T}_{\mathrm{R}}$ and $\mathrm{T}_{\mathrm{E}}$. The simulation parameters were $\alpha=20^{\circ}, \Delta \mathrm{B}_{\mathrm{z}, \mathrm{C}}=1 \mathrm{nT}$, $\mathrm{T}_{\mathrm{R}}=[20-260] \mathrm{ms}$, and $\mathrm{T}_{\mathrm{E}}=[10-140] \mathrm{ms}$. The RF pulse width, prephaser, and spoiler gradient durations were set to $\tau_{\alpha}=2 \mathrm{~ms}, \mathrm{~T}_{\text {pre }}=0.5 \mathrm{~ms}$, and $\mathrm{T}_{\mathrm{sp}}=0.6 \mathrm{~ms}$, respectively. Impossible combinations of $T_{E}$ and $T_{R}$ (i.e., $T_{E}>T_{R}$ ) were ignored. The image SNR was adjusted according to a choice of lowest possible sampling BWs.

- To find the most efficient parameters settings for SSFP-FID ${ }_{\mathrm{FCI}}$, the effect of the tip angle on the efficiency was also investigated. The simulation parameters were $\alpha=\left[5^{\circ}-90^{\circ}\right], \mathrm{T}_{\mathrm{E}}=[10-120] \mathrm{ms}$, and $\mathrm{T}_{\mathrm{R}}=[20-1500] \mathrm{ms}$. For each tip angle, the normalized maximal efficiency and the corresponding $T_{E}$ and $T_{R}$ were selected and the results plotted with respect to $\alpha$.

As a last step, we explored via simulations the loss in efficiency when using multi-gradient-echo summation by means of multiple monopolar or bipolar readout gradients to prevent image distortions resulting from using low BWs at long $\mathrm{T}_{\mathrm{ES}}$ (MESE) or $\mathrm{T}_{\mathrm{R}}$ (SSFP-FID). The number of summed echoes during a readout period $\mathrm{N}_{\mathrm{m}}$ was varied in the range [1-16]. For MESE, $\mathrm{T}_{\mathrm{ES}}=80 \mathrm{~ms}$ was selected and the duration of the added prephaser gradients was $\mathrm{T}_{\text {pre }}=0.5 \mathrm{~ms}$. The other parameters were kept unchanged from the prior simulations. For SSFP-FID, $\mathrm{T}_{\mathrm{R}}=160 \mathrm{~ms}$ was used.

\section{Experiments}

All experiments were performed on a 3T MRI scanner (MAGNETOM Prisma; Siemens Healthcare, Erlangen, Germany) equipped with a 64-channel head coil (an adaptive combine algorithm (26) was used to combine the received MRI signals from each coil element). The current waveforms were created by an arbitrary waveform generator (33500B; Keysight Technologies, Santa Clara, CA, USA) and a home-made voltage-to-current converter (Fig. 2a), and injected into a phantom by recessed copper electrodes (Fig. 2b,c). Two different phantoms were used: Phantom 1 was spherical and filled with doped saline having relaxation times similar to brain tissue (Fig. 2b). Phantom 2 was cylindrical, filled with similar doped saline and having a piece of organic chicken meat placed in its center (Fig. 2c).

For MESE, the following experiments were performed:

- The importance of properly designed crusher gradients to prevent the impact of nonideal RF refocusing pulses on the phase evolution was demonstrated in Phantom 1. Three different MESE pulse sequences were tested and their current-induced phase evolutions over echoes were compared. In the first two sequences, the momentum of the crusher gradients 
were kept constant and refocusing RF pulses of $150^{\circ}$ and $180^{\circ}$ were used to explore effects of $B_{1}$ inhomogeneity. In the third sequence, the momentum of the crusher gradients was systematically changed and $180^{\circ}$ refocusing $\mathrm{RF}$ pulses were used: The crusher momentums were either doubled between subsequent echoes or the crusher gradient direction was switched. In all sequences, the first crusher gradient was optimized for creating a $4 \pi$ intravoxel phase dispersion (27). The other sequence parameters were: field of view $(\mathrm{FOV})=200 \times 200 \mathrm{~mm}^{2}$, image matrix $=128 \times 128$, slice thickness $\Delta \mathrm{z}=3 \mathrm{~mm}$, $\mathrm{N}_{\text {avg }}=1, \mathrm{~N}_{\text {echo }}=7$, injected current magnitude $\mathrm{I}_{\mathrm{C}}=1$ $\mathrm{mA}, \mathrm{T}_{\mathrm{ES}}=[40,60] \mathrm{ms}$, and $\mathrm{T}_{\mathrm{D}}=510 \mathrm{~ms}$.

- Efficiency measurements were performed in Phantom 1. The measurement parameters were $\mathrm{FOV}=300 \times 300 \mathrm{~mm}^{2}, \quad$ image matrix $=256 \times 256$, $\Delta \mathrm{z}=5 \mathrm{~mm}, \mathrm{~T}_{\mathrm{D}}=510 \mathrm{~ms}, \mathrm{~N}_{\mathrm{avg}}=1, \mathrm{~N}_{\text {echo }}=[1-8]$, and $\mathrm{I}_{\mathrm{C}}=0.5 \mathrm{~mA}$. The measurements were repeated by varying the echo spacing $\mathrm{T}_{\mathrm{ES}}=[20-160] \mathrm{ms}$ with 20 ms intervals. In each experiment, the lowest possible bandwidth (BW) was used. The experiments were repeated with opposite polarity bipolar current injection in order to eliminate systematic phase artifacts and to increase the SNR of the experiment (21). The phase evolution over echoes, combined $\Delta \mathrm{B}_{\mathrm{z}, \mathrm{c}}$ across echoes, SNR of the combined $\Delta \mathrm{B}_{\mathrm{z}, \mathrm{C}}$, and efficiency were determined from the measurements (the root-mean-square SNR of the combined $\Delta \mathrm{B}_{\mathrm{z}, \mathrm{c}}$ and the efficiency values were calculated in the region of interest ROI shown in Figs. 4a and 7a). To estimate the preserved signal ratio $\beta_{\mathrm{RF}}$ influenced by $\mathrm{RF}$ inhomogeneity, the signal decay across multiple echoes for $\mathrm{T}_{\mathrm{ES}}=20 \mathrm{~ms}$ was compared with the real $\mathrm{T}_{2}$ decay determined from the first echoes when varying $\mathrm{T}_{\mathrm{ES}}$ from $20 \mathrm{~ms}$ to $160 \mathrm{~ms}$.

For SSFP-FID, the following experiments were performed:

- SSFP-FID measurements were repeated for different current magnitudes to validate the simulated dependency on $\Delta \mathrm{B}_{\mathrm{z}, \mathrm{c}}$ of the transverse magnetization phase. The measurements were performed with both

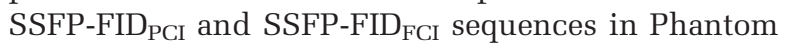
1 and their phase sensitivities were compared. The sequence parameters were $\mathrm{FOV}=375 \times 375 \mathrm{~mm}^{2}$, image $\operatorname{matrix}=256 \times 256, \Delta \mathrm{z}=3 \mathrm{~mm}, \quad \alpha=60^{\circ}$, $\mathrm{N}_{\mathrm{avg}}=16 \times 2$ (16 separate averages for each steady state). The experiments were repeated for three different repetition times $\mathrm{T}_{\mathrm{R}}=[10,30,50] \mathrm{ms}$ (with $\mathrm{T}_{\mathrm{E}}=\mathrm{T}_{\mathrm{R}} / 2$ ) and for different current magnitudes $\mathrm{I}_{\mathrm{C}}=[-10$ to 10$] \mathrm{mA}$ with $2-\mathrm{mA}$ intervals. The lowest possible BW was always selected to maximize SNR.

- Efficiency measurements were performed in Phan-

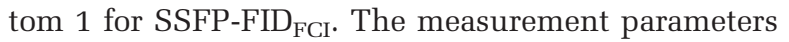
were $\mathrm{FOV}=192 \times 192 \mathrm{~mm}^{2}$, image matrix $=128 \times 128$, $\Delta \mathrm{z}=3 \mathrm{~mm}, \alpha=20^{\circ}, \mathrm{N}_{\mathrm{avg}}=2 \times 2$, and $\mathrm{I}_{\mathrm{C}}=1 \mathrm{~mA}$. The experiment was repeated for different echo times $\mathrm{T}_{\mathrm{E}}=[10-140] \mathrm{ms}$ with 10-ms intervals and repetition times $\mathrm{T}_{\mathrm{R}}=[20-260] \mathrm{ms}$ with 20-ms intervals. Impossible combinations of $\mathrm{T}_{\mathrm{E}}$ and $\mathrm{T}_{\mathrm{R}}$ (i.e., $\mathrm{T}_{\mathrm{E}}>\mathrm{T}_{\mathrm{R}}$ ) were ignored. In each measurement, bipolar currents were injected to create dual steady states with opposite current-induced phases. From these steady-state data, phase difference images were calculated and $\Delta \mathrm{B}_{\mathrm{z}, \mathrm{c}}$ was reconstructed by using $\mathrm{m}_{\mathrm{seq}}=\partial\left(\angle \mathrm{M}_{\mathrm{SS} 1}-\angle \mathrm{M}_{\mathrm{SS} 2}\right) /$ $\partial \Delta \mathrm{B}_{\mathrm{z}, \mathrm{c}}$ in the simulations. The SNR of the $\Delta \mathrm{B}_{\mathrm{z}, \mathrm{c}}$ images and the efficiency were then determined.

In addition, two experiments with the optimized

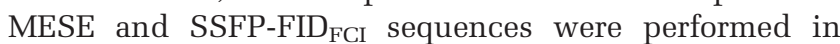
Phantom 1 in order to directly compare their efficiencies. The sequence parameters were $\mathrm{FOV}=256 \times 256 \mathrm{~mm}^{2}$, image matrix $=128 \times 128, \mathrm{~N}_{\mathrm{avg}}=1 \times 2$, and $\mathrm{I}_{\mathrm{C}}=1 \mathrm{~mA}$. The optimized parameters were selected as $\mathrm{T}_{\mathrm{ES}}=80 \mathrm{~ms}$, $\mathrm{T}_{\mathrm{D}}=1.5 \mathrm{~s}$, and $\mathrm{N}_{\text {echo }}=3$ for MESE; and $\mathrm{T}_{\mathrm{E}}=60 \mathrm{~ms}$, $\mathrm{T}_{\mathrm{R}}=120 \mathrm{~ms}$, and $\alpha=30^{\circ}$ for SSFP-FID $\mathrm{FCI}$.

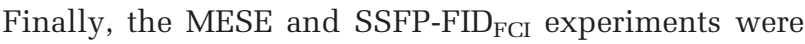
performed in Phantom 2 to demonstrate the sequence performance for a nonhomogenous geometry involving a chicken meat piece. The experiments were performed for both vertical and horizontal electrical current injection. The MESE measurement parameters were $\mathrm{T}_{\mathrm{ES}}=80 \mathrm{~ms}$, $\mathrm{T}_{\mathrm{D}}=510 \mathrm{~ms}, \quad \mathrm{~N}_{\text {echo }}=3, \quad \mathrm{FOV}=192 \times 192 \mathrm{~mm}^{2}$, image matrix $=128 \times 128, \Delta \mathrm{z}=3 \mathrm{~mm}, \mathrm{BW}=100 \mathrm{~Hz} /$ pixel, $\mathrm{N}_{\text {avg }}=1$,

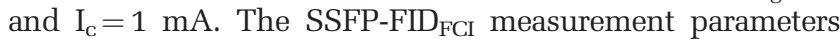
were $\alpha=20^{\circ}, \mathrm{T}_{\mathrm{E}}=15 \mathrm{~ms}, \mathrm{~T}_{\mathrm{R}}=30 \mathrm{~ms}, \quad \mathrm{FOV}=192 \times$ $192 \mathrm{~mm}^{2}$, image matrix $=128 \times 128, \Delta \mathrm{z}=3 \mathrm{~mm}, \quad \mathrm{BW}=$ $100 \mathrm{~Hz} /$ pixel, $\mathrm{N}_{\text {avg }}=16 \times 2$, and $\mathrm{I}_{\mathrm{C}}=1 \mathrm{~mA}$.

\section{RESULTS}

\section{MESE}

As a first step, the importance of properly chosen crusher gradients is demonstrated. When keeping the crusher gradients constant, the stimulated echo pathways caused by the nonideal refocusing pulses have a clear impact on the phase evolution (Fig. 3a,b). This effect is more prominent for $150^{\circ}$ refocusing pulses (Fig. 3a), but is also clearly visible in the later echoes for $180^{\circ}$ refocusing pulses (Fig. 3b). In contrast, systematically doubling the area of the crusher gradients between consecutive echoes in combination with changing crusher direction (27) successfully eliminates the unwanted echo pathways, resulting in the expected linear phase increase over echoes (Fig. 3c).

The results of the efficiency simulations and measurements for a fixed $\mathrm{T}_{\mathrm{D}}$ are shown in Figure 4. As an example, Figure $4 \mathrm{a}$ shows the combined $\Delta \mathrm{B}_{\mathrm{z}, \mathrm{c}}$ image for eight echoes $\left(\mathrm{T}_{\mathrm{ES}}=20 \mathrm{~ms}, \mathrm{~T}_{\mathrm{R}}=670 \mathrm{~ms}, \mathrm{BW}=125 \mathrm{~Hz} /\right.$ pixel, and $\mathrm{I}_{\mathrm{c}}=0.5 \mathrm{~mA}$ ). The measured $\Delta \mathrm{B}_{\mathrm{z}, \mathrm{c}}$ pattern is in agreement with the current flowing from top to bottom. As expected, the weak current strength did not cause significant geometric distortions despite being applied throughout the readout periods. Figure $4 \mathrm{~b}$ shows the measured phase evolution across echoes for $\mathrm{T}_{\mathrm{ES}}=[20$ 160] ms, confirming the linear phase evolution for the optimized crusher gradients. The simulated and measured dependencies of the efficiency of the combined $\Delta \mathrm{B}_{\mathrm{z}, \mathrm{C}}$ on $\mathrm{N}_{\text {echo }}$ and $\mathrm{T}_{\mathrm{ES}}$ are shown in Figure 4e,f. Because the simulations give only relative efficiency values, both plots are normalized to their individual maxima. The 


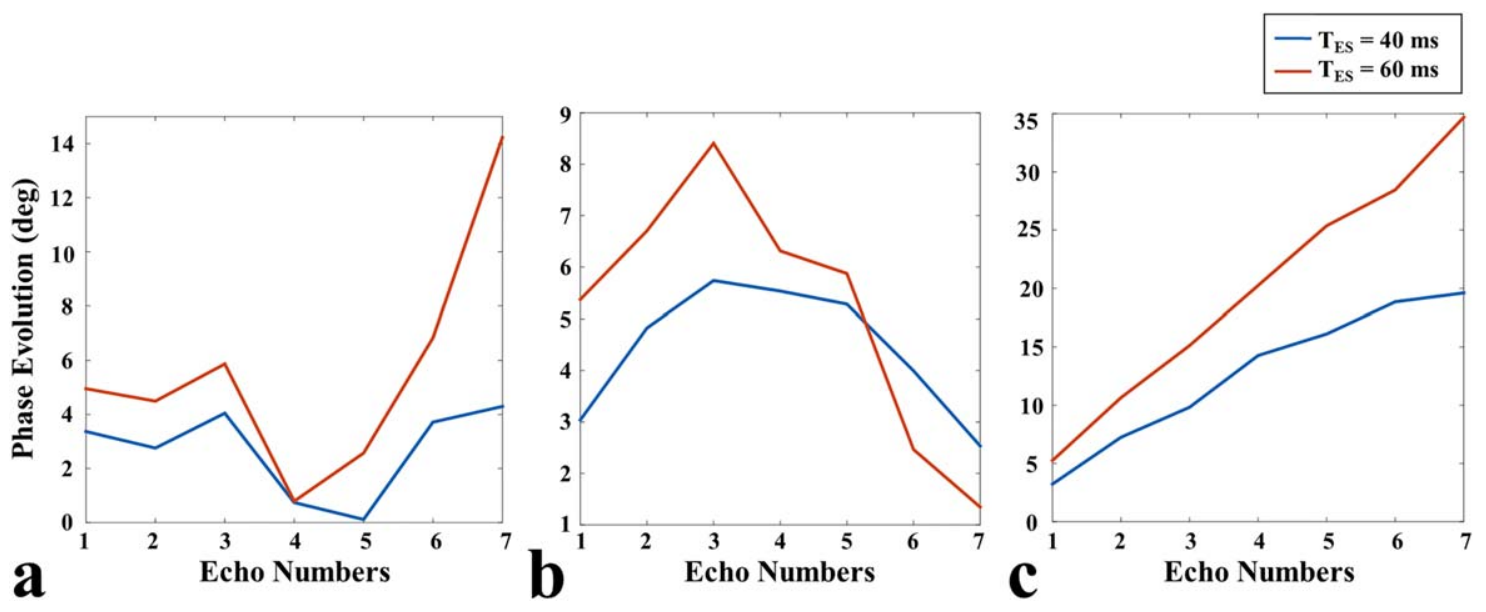

FIG. 3. Phase evolution for MESE across echoes, tested for two different echo spacings $T_{E S}=[40,60]$ ms. (a) The refocusing pulse tip angle is $150^{\circ}$, and the gradient areas and axes are kept identical across echoes. This results in both primary and stimulated echo pathways. (b) The refocusing pulse tip angle is $180^{\circ}$, and the gradients are kept identical. This also causes primary and stimulated echo pathways. (c) The refocusing pulse tip angle is $180^{\circ}$ and the gradients are systematically varied, resulting in the selection of only the primary echo pathway and a linear phase accumulation.

simulations and experimental results are in good agreement. The corresponding results for the SNR are shown in Supporting Figure S1. While the SNR increases with the number of acquired echoes, the highest efficiency occurs for $\mathrm{N}_{\text {echo }}=[2,3]$. This indicates that the later echoes contribute only weakly to the combined $\Delta \mathrm{B}_{\mathrm{z}, \mathrm{c}}$ image. Interestingly, the highest efficiency is found for rather long echo times of $\mathrm{T}_{\mathrm{ES}}=[80-100] \mathrm{ms}$. In order to make a comparison with our results and the literature, singleecho SE with $\mathrm{T}_{\mathrm{E}}=60 \mathrm{~ms}$ is selected as a reference $(12,21)$. The selection of the most efficient sequence parameters results in an efficiency increase of $41 \%$.

So far, the efficiency was only assessed for a single slice and a fixed $\mathrm{T}_{\mathrm{D}}$ value. Figure $5 \mathrm{a}$ shows the simulated efficiency also with respect to $\mathrm{T}_{\mathrm{D}}$ and different number of slices, normalized to the maximum across all simulations. For each $\mathrm{T}_{\mathrm{D}}$, the most efficient $\mathrm{T}_{\mathrm{ES}}$ and $\mathrm{N}_{\text {echo }}$ were selected. In addition, the corresponding $\mathrm{T}_{\mathrm{ES}}$ and $\mathrm{N}_{\text {echo }}$ for a single slice are shown in Figure 5b. For a single slice, the efficiency peaks for a rather long $\mathrm{T}_{\mathrm{D}}$ of around 1.5 seconds, indicating that a substantial recovery of the longitudinal magnetization before re-excitation is optimal. Interestingly, the maximal efficiency can still be reached for three to four slices (as expected, $\mathrm{T}_{\mathrm{D}}$ reaches 0 in this case) and a clear drop occurs only for a higher number of slices. This shows that multi-slice MESE MREIT is feasible without losing efficiency. The optimized $\mathrm{T}_{\mathrm{ES}}$ is around $80 \mathrm{~ms}$ and the best-performing $\mathrm{N}_{\text {echo }}$ increases from 2 to 4 when increasing $\mathrm{T}_{\mathrm{D}}$.

\section{SSFP-FID}

Simulated dependencies of the transverse magnetization phase on $\Delta \mathrm{B}_{\mathrm{z}, \mathrm{c}}$ are shown in Figure $6 \mathrm{a}$ for both sequence variants. The results indicate that the dependency of the steady-state phase on $\Delta \mathrm{B}_{\mathrm{z}, \mathrm{c}}$ can be well linearized for weak injection currents. Judging from the slope of the phase dependencies around 0, SSFP-FID ${ }_{\text {PCI }}$ is $37 \%$ and SSFP-FID $_{\mathrm{FCI}}$ is $73 \%$ more sensitive compared to the standard spin echo case. Measured dependencies of the steady-state phase on the injected current strength $\mathrm{I}_{\mathrm{C}}$ are shown in Figure 6b (SSFP-FID ${ }_{\mathrm{PCI}}$ ) and 6c (SSFP-FID FCI $_{1}$ ). The measured steady-state phase depends linearly on $\Delta \mathrm{B}_{\mathrm{z}, \mathrm{C}}$ for both variants. SSFP-FID $\mathrm{FCI}_{\mathrm{F}}$ is $26 \%$ more sensitive than SSFP-FID PCI $_{\text {for }} \mathrm{T}_{\mathrm{R}}=50 \mathrm{~ms}$. This is in good agreement with the simulations (Fig. $6 a)$, using the linear relationship between $\Delta \mathrm{B}_{\mathrm{z}, \mathrm{c}}$ and $\mathrm{I}_{\mathrm{C}}$. In contrast to the phase, the steady-state magnitude has a flat dependency on $\Delta \mathrm{B}_{\mathrm{z}, \mathrm{c}}$ for both variants for the weak injected current strengths tested here $\left(\Delta \mathrm{B}_{\mathrm{z}, \mathrm{C}}\right.$ close to 0), both in the simulations (Supporting Fig. S2a) and measurements (Supporting Fig. S2b,c).

The results of the efficiency simulations and measure-

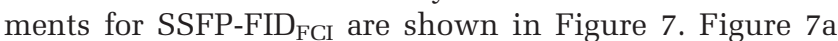
shows the reconstructed $\Delta \mathrm{B}_{\mathrm{z}, \mathrm{c}}$ image from the averaged phase difference images between the two alternating steady states for $\alpha=20^{\circ}, \mathrm{T}_{\mathrm{R}}=20 \mathrm{~ms}, \mathrm{~T}_{\mathrm{E}}=10 \mathrm{~ms}$, and $\mathrm{I}_{\mathrm{C}}=1 \mathrm{~mA}$. The image is in agreement with the current flowing from top to bottom, and, as expected, the weak current strength did not cause geometric distortions despite being applied throughout the readout periods. However, significant signal drop attributed to $\mathrm{T}_{2}^{*}$ decay is observed in the poorly shimmed regions, such as near the electrodes and phantom edges. Figure $7 \mathrm{~b}$ shows the measured phase evolution for $\mathrm{T}_{\mathrm{E}}=[10-140] \mathrm{ms}$ and $\mathrm{T}_{\mathrm{R}}=[20-260] \mathrm{ms}$. The steady-state phase increases linearly with increasing $\mathrm{T}_{\mathrm{E}}$. There is no significant phase change observed for different $T_{R}$ values when $T_{E}$ is kept constant.

Figure 7c,d shows the simulation and experimental results for the efficiencies of $\Delta \mathrm{B}_{\mathrm{z}, \mathrm{C}}$, normalized to their individual maxima (Supporting Fig. S3a,b depicts the corresponding SNR plots). Simulations and experimental results agree well. The maximal efficiency occurs for $\mathrm{T}_{\mathrm{E}}=[60-90] \mathrm{ms}$ and $\mathrm{T}_{\mathrm{R}}=[120-180] \mathrm{ms}$. The highest efficiency is mostly observed when $\mathrm{T}_{\mathrm{E}}=\mathrm{T}_{\mathrm{R}} / 2$, attributed to the symmetric data acquisition. Interestingly, the highest efficiency occurs for rather long echo times. This indicates that the increased signal strength attributed to 


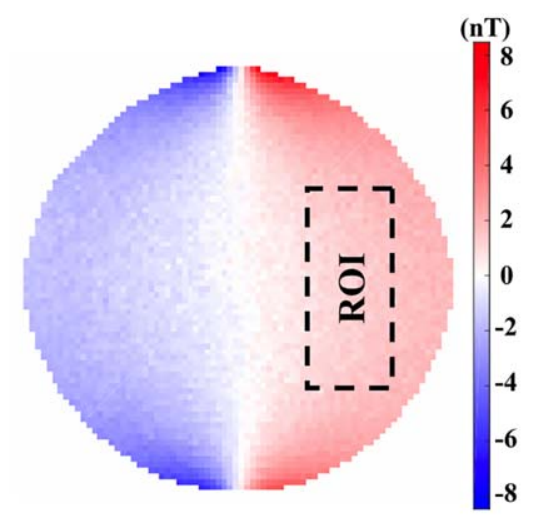

$\mathbf{a}$

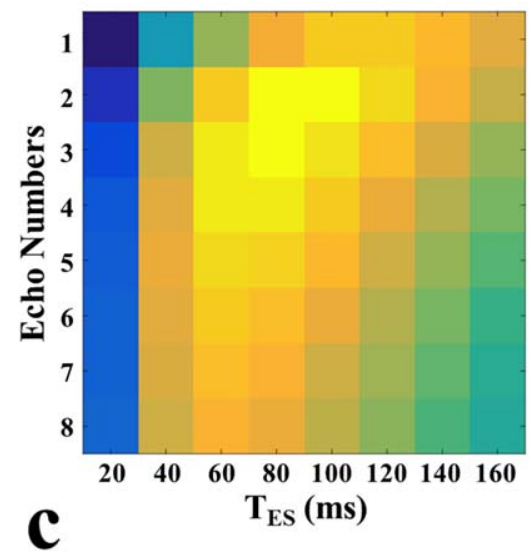

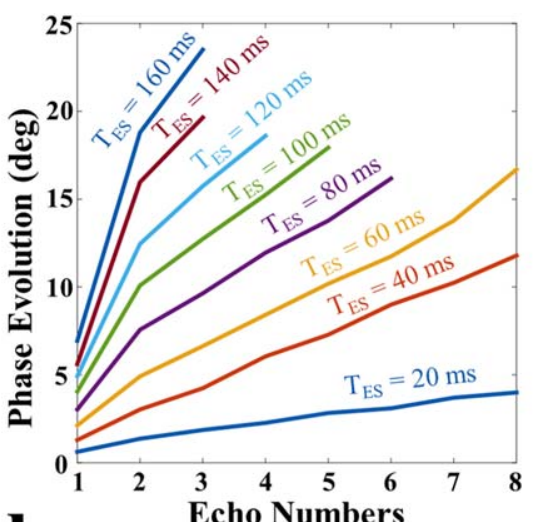

b

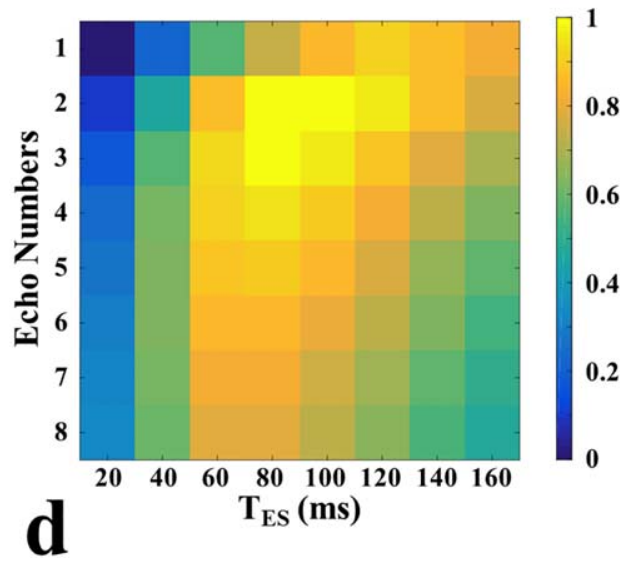

FIG. 4. MESE simulation and measurement results. (a) Measured combined $\Delta \mathrm{B}_{\mathrm{z}, \mathrm{c}}$ image for $\mathrm{N}_{\text {slice }}=1, \mathrm{~N}_{\mathrm{avg}}=1, \mathrm{~N}_{\mathrm{echo}}=8, \mathrm{~T}_{\mathrm{ES}}=20 \mathrm{~ms}$, $T_{D}=510 \mathrm{~ms}, B W=125 \mathrm{~Hz} /$ pixel, and $I_{C}=0.5 \mathrm{~mA}$. The current is injected in a vertically downward direction. The ROI used to calculate the SNR and the efficiency is shown by the dashed lines. (b) Measured phase evolution over echo numbers for different $T_{E S}$. (c) Simulated efficiency. (d) Measured efficiency. The results in (c) and (d) are normalized relative to their maximal values. The measurement and simulation parameters in $(\mathbf{b}-\mathbf{d})$ are $\mathrm{FOV}=300 \times 300 \mathrm{~mm}^{2}$, image matrix $=256 \times 256, \Delta \mathrm{z}=5 \mathrm{~mm}, \mathrm{~N}_{\text {slice }}=1, \mathrm{~N}_{\text {avg }}=1, \mathrm{~N}_{\mathrm{echo}}=[1-8]$, $T_{E S}=[20-160] \mathrm{ms}, T_{D}=510 \mathrm{~ms}, T_{1}=1.1$ seconds, $T_{2}=100 \mathrm{~ms}, T_{2}^{*}=50 \mathrm{~ms}$, and $\mathrm{I}_{\mathrm{C}}=0.5 \mathrm{~mA}$. In both measurements and simulations, the lowest possible BW is selected to maximize the SNR of the MR magnitude image.

increased $\mathrm{T}_{1}$ recovery and higher phase accumulation outweighs the stronger impact of $\mathrm{T}_{2}^{*}$ decay at longer $\mathrm{T}_{\mathrm{E}}$.

So far, the results were assessed for a fixed tip angle $\alpha$ of $20^{\circ}$. Figure 8 shows the simulated efficiency also with respect to changes in the tip angle for SSFP-FID FCI $_{\text {, nor- }}$ malized to the maximum across all simulations. The most efficient $T_{E}$ and $T_{R}$ values were selected for each tip angle. The maximal efficiency occurs around $\alpha=30^{\circ}$ and decreases slightly for higher tip angles (Fig. 8a). The corresponding optimized $\mathrm{T}_{\mathrm{E}}$ and $\mathrm{T}_{\mathrm{R}}$ values are shown in Figure 8b,c. The optimized echo time $\mathrm{T}_{\mathrm{E}}$ varies in the range between 50 and $80 \mathrm{~ms}$ (i.e., it is roughly in the

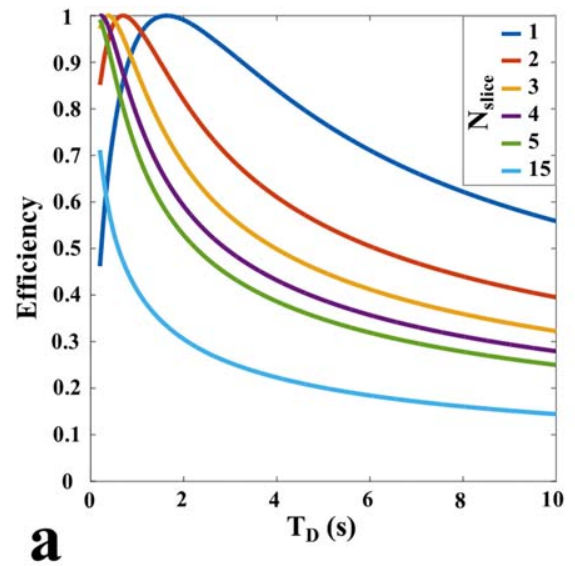

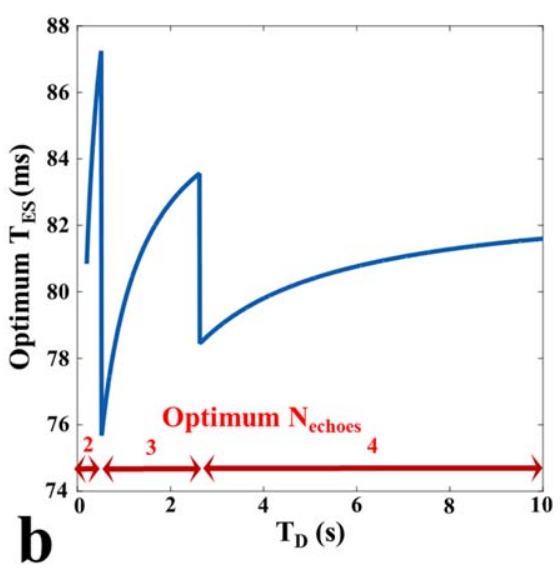

FIG. 5. (a) Efficiency of MESE with respect to $T_{D}$, assessed for slices $\mathrm{N}_{\text {slice }}=[1-5,15]$ and normalized to the peak across all simulations. For each $T_{D}, T_{E S}, B W$, and $N_{\text {echo }}$ were optimized. (b) Corresponding echo spacing $\mathrm{T}_{\mathrm{ES}}$ and number of echoes $\mathrm{N}_{\text {echo }}$ for $\mathrm{N}_{\text {slice }}=1$. 

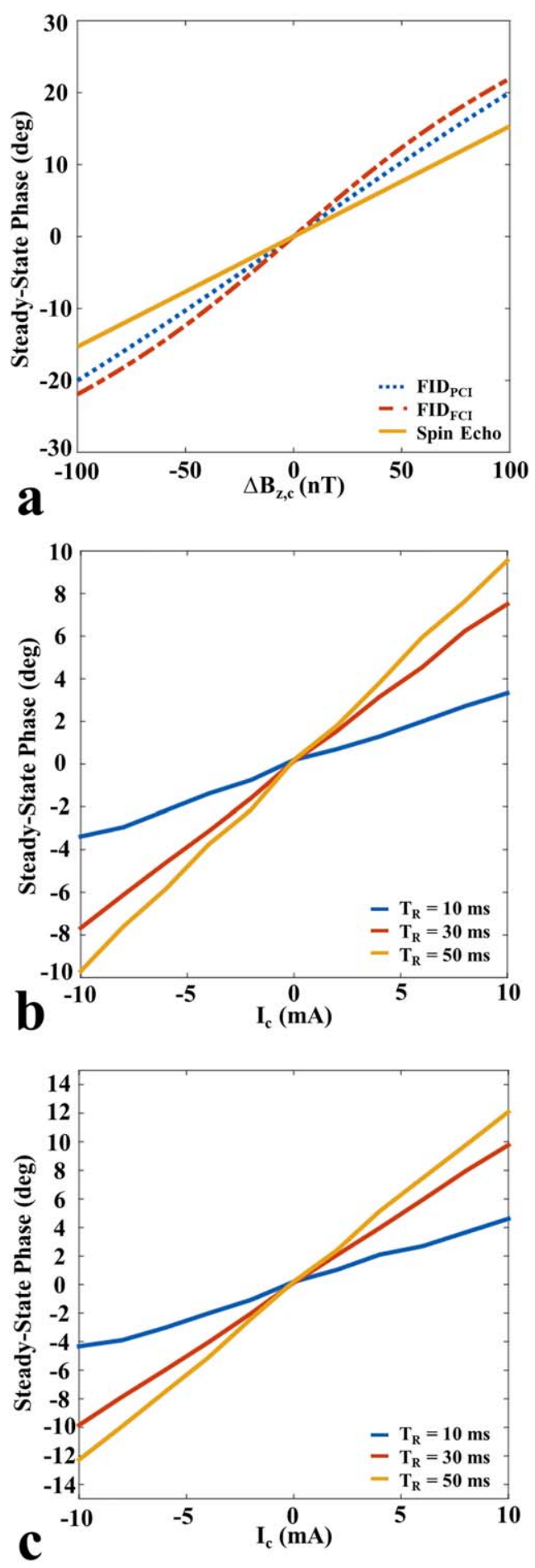

FIG. 6. (a) Simulated dependency of phase of the steady-state

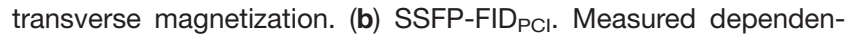
cies of the phase of the transverse magnetization. (c) SSFP$\mathrm{FID}_{\mathrm{FCl}}$. Measured dependencies of the phase of the transverse magnetization. (b,c) The results were obtained for $T_{R}=[10,30,50]$ $\mathrm{ms}$ and $\mathrm{I}_{\mathrm{C}}=[-10$ to 10$] \mathrm{mA}$.

range of the selected $\mathrm{T}_{2}^{*}$ ) and reaches a plateau for higher tip angles. This is mainly attributed to the large signal loss for sampling times much longer than $\mathrm{T}_{2}^{*}$. The optimized $\mathrm{T}_{\mathrm{R}}$ increases with tip angle.

\section{Comparison Between MESE and SSFP-FID}

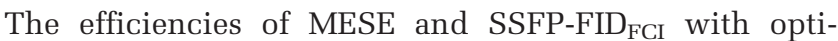
mized sequence parameters were directly compared. SSFP-FID ${ }_{\text {FCI }}$ has a $0.07 \%$ higher SNR for $\Delta \mathrm{B}_{\mathrm{z}, \mathrm{C}}$ compared to MESE, but gives a 3 times higher efficiency. This suggests that SSFP-FID may be very useful for rapid imaging. However, the SSFP-FID causes a significant efficiency decrease in inhomogenous regions and the image is significantly distorted, whereas MESE can preserve both. In addition, multi-slice SSFP-FID applications will cause significant efficiency decrease, whereas MESE preserves the efficiency.

\section{Maximal Efficiency for Multi-Gradient-Echo Acquisition}

The most efficient parameter ranges in both MESE and SSFP-FID experiments result in very low BWs, which cause geometric image distortions attributed to $\mathrm{B}_{0}$ inhomogeneities. This effect can be prevented by acquiring multiple gradient echoes during each readout period at a higher BW, which are then added (17). Here, the efficiency decrease attributed to the time required for the additional prephaser gradients and gradient switching and corresponding BW were simulated. For both monopolar (Fig. 9a) and bipolar readout gradients (Fig. 9b), only a moderate loss of efficiency of less than $10 \%$ occurred for up to 16 gradient echoes. This indicates that the summation of multiple gradient echoes may be a suitable way for preventing geometric distortions caused by otherwise low BWs while maintaining acquisition efficiency.

\section{Experiments in a Phantom With Inhomogeneous Geometry}

MESE and SSFP-FID FCI images were obtained in Phantom 2 containing a piece of chicken meat to assess the sequence performance for nonuniform structures. The sequence parameters were chosen in pilot trials to optimize efficiency as far as possible while maintaining image quality at an acceptable level. The results are reported for vertical and horizontal directions of current injection. For MESE, the combined MR magnitude image is shown in Figure 10a, and the combined $\Delta \mathrm{B}_{\mathrm{z,c}}$ images for horizontal and vertical current injection are depicted

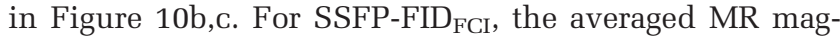
nitude image is shown in Figure 10d, and the $\Delta \mathrm{B}_{\mathrm{z}, \mathrm{c}}$ images are given in Figure 10e,f. Both sequences allow accurate $\Delta \mathrm{B}_{\mathrm{z}, \mathrm{C}}$ measurements for the saline regions of the phantom, despite using a low current magnitude of $\mathrm{I}_{\mathrm{C}}=1$ $\mathrm{mA}$. The impact of the chicken piece on the $\Delta \mathrm{B}_{\mathrm{z}, \mathrm{c}}$ distribution is clearly visible in particular for the horizontal current injection. In MESE, the SNR of combined $\Delta \mathrm{B}_{\mathrm{z}, \mathrm{c}}$ image is lower in the region of the chicken meat, which can be explained by the chosen $\mathrm{T}_{\mathrm{ES}}(80 \mathrm{~ms})$, which exceeds $\mathrm{T}_{2}$ in this region (50 ms) and results in a low signal magnitude (Fig. 10a). This is less of an issue for SSFP-FID $_{\text {FCI }}$, where a short $\mathrm{T}_{\mathrm{E}}(15 \mathrm{~ms})$ was chosen.

\section{DISCUSSION AND CONCLUSIONS}

Successful in-vivo applications of MRCDI and MREIT will require that magnetic fields created by weak injection 


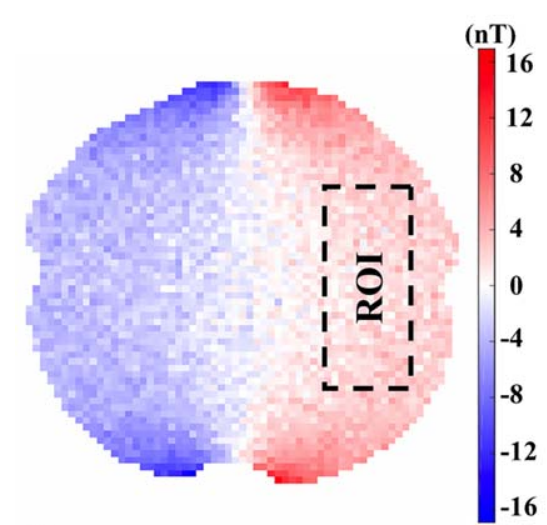

\section{a}
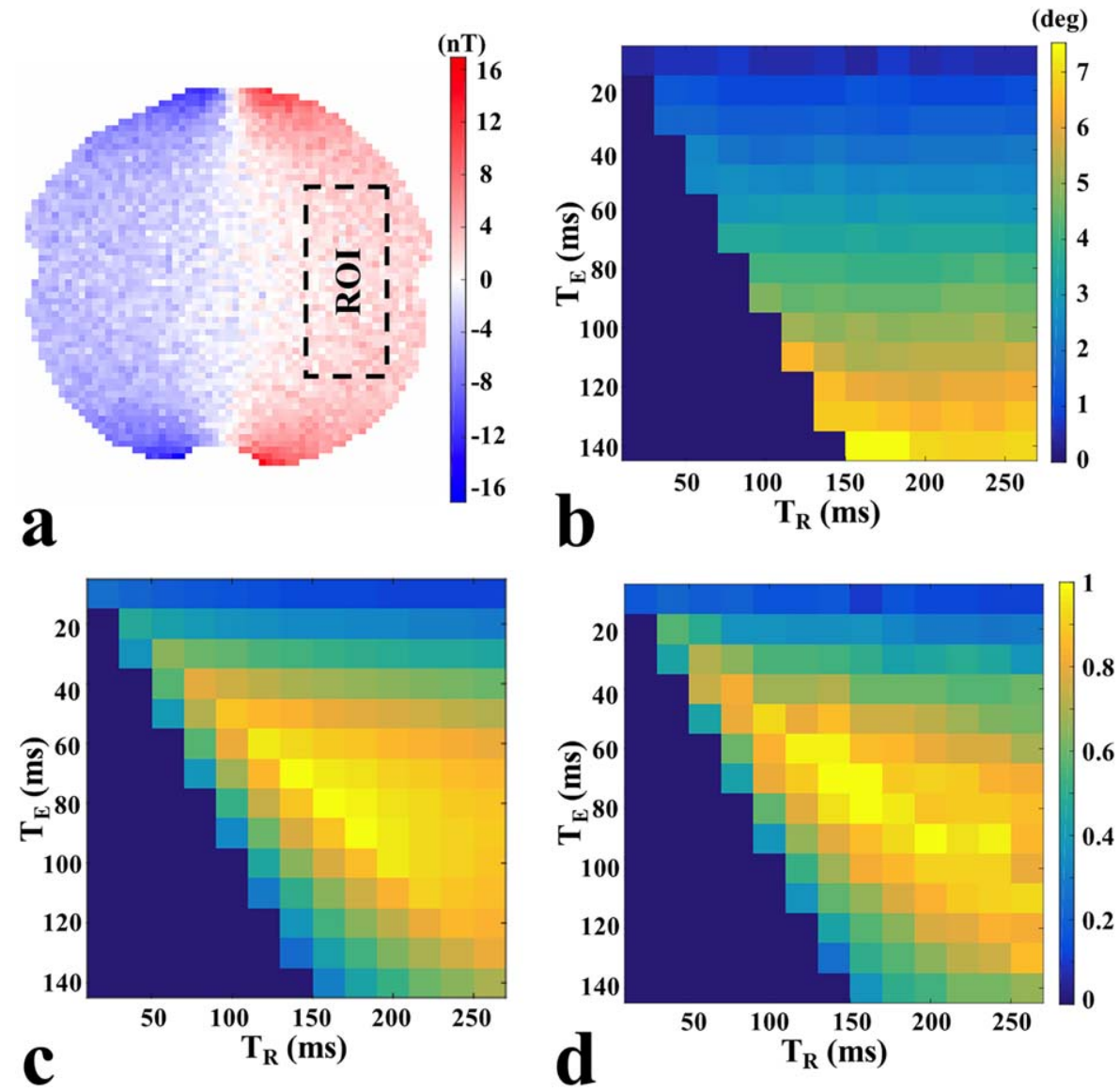

FIG. 7. Simulations and measurement results for SSFP-FID $D_{F C l}$. (a) Measured $\Delta B_{z, c}$ image for $I_{C}=1 \mathrm{~mA}, \alpha=20^{\circ}, T_{R}=20 \mathrm{~ms}$, and $T_{E}=10$ ms. The ROI used to calculate the SNR and the efficiency is shown by the dashed lines. (b) Measured phase evolution. (c) Simulated efficiency (normalized to the maximum) of the reconstructed $\Delta \mathrm{B}_{z, c}$ image. (d) Measured efficiency (normalized to the maximum) of the reconstructed $\Delta \mathrm{B}_{z, c}$ image. The measurement and simulation parameters in (b-d) are $\mathrm{N}_{\mathrm{avg}}=2 \times 2$ (two separate averages for each steady state), $T_{E}=[10-140] \mathrm{ms}, T_{R}=[20-260] \mathrm{ms}, T_{1}=1.1$ seconds, $T_{2}=100 \mathrm{~ms}, T_{2}^{*}=50 \mathrm{~ms}$, voxel size $=1.5 \times 1.5 \times 3 \mathrm{~mm}^{3}$, image matrix $=256 \times 256$, and $I_{C}=1 \mathrm{~mA}$. In both measurements and simulations, readout was symmetrical around $T_{E}$ and the lowest possible $B W$ is selected to maximize SNR of the MR magnitude image. For impossible combinations of $T_{E}$ and $T_{R}$ (i.e., $\left.T_{E}>T_{R}\right)$, the $S N R$ and efficiency were set to 0 .

currents of 1 to $2 \mathrm{~mA}$ are reliably measured in clinically relevant acquisition times. We therefore performed systematic sensitivity analyses to optimize the efficiency of two MREIT pulse sequences based on MESE and SSFPFID, respectively, while assuming relaxation times similar to human brain tissue at $3 \mathrm{~T}$. For both sequence types, the current injection was extended into the readout periods to maximize sensitivity. Considering the low targeted current strengths, we suggest that this is feasible without causing relevant image distortions so that correction
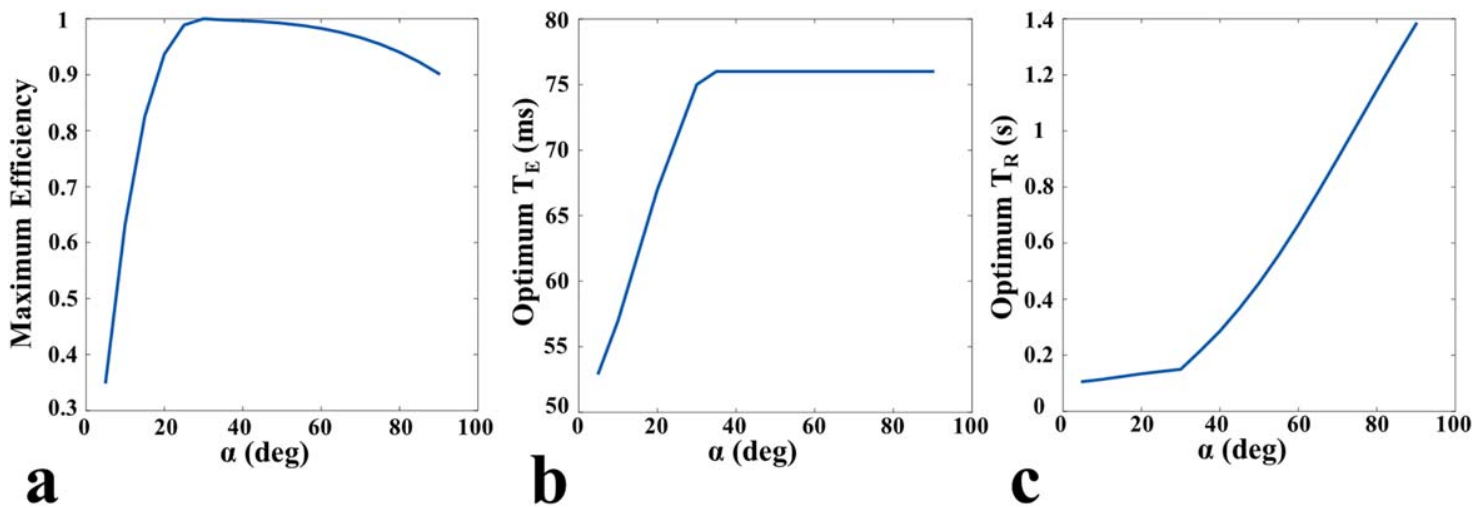

FIG. 8. Simulated efficiencies for different tip angles for SSFP-FID $\mathrm{FCl}_{\text {. }}$ (a) Normalized maximal efficiency dependence on the tip angle. (b) Corresponding optimal $T_{E}$ values. (c) Corresponding optimal $T_{R}$ values. 
FIG. 9. Efficiency loss and corresponding BW increase in case of multi-echo acquisition: (a) monopolar readout gradient and (b) bipolar readout gradient.
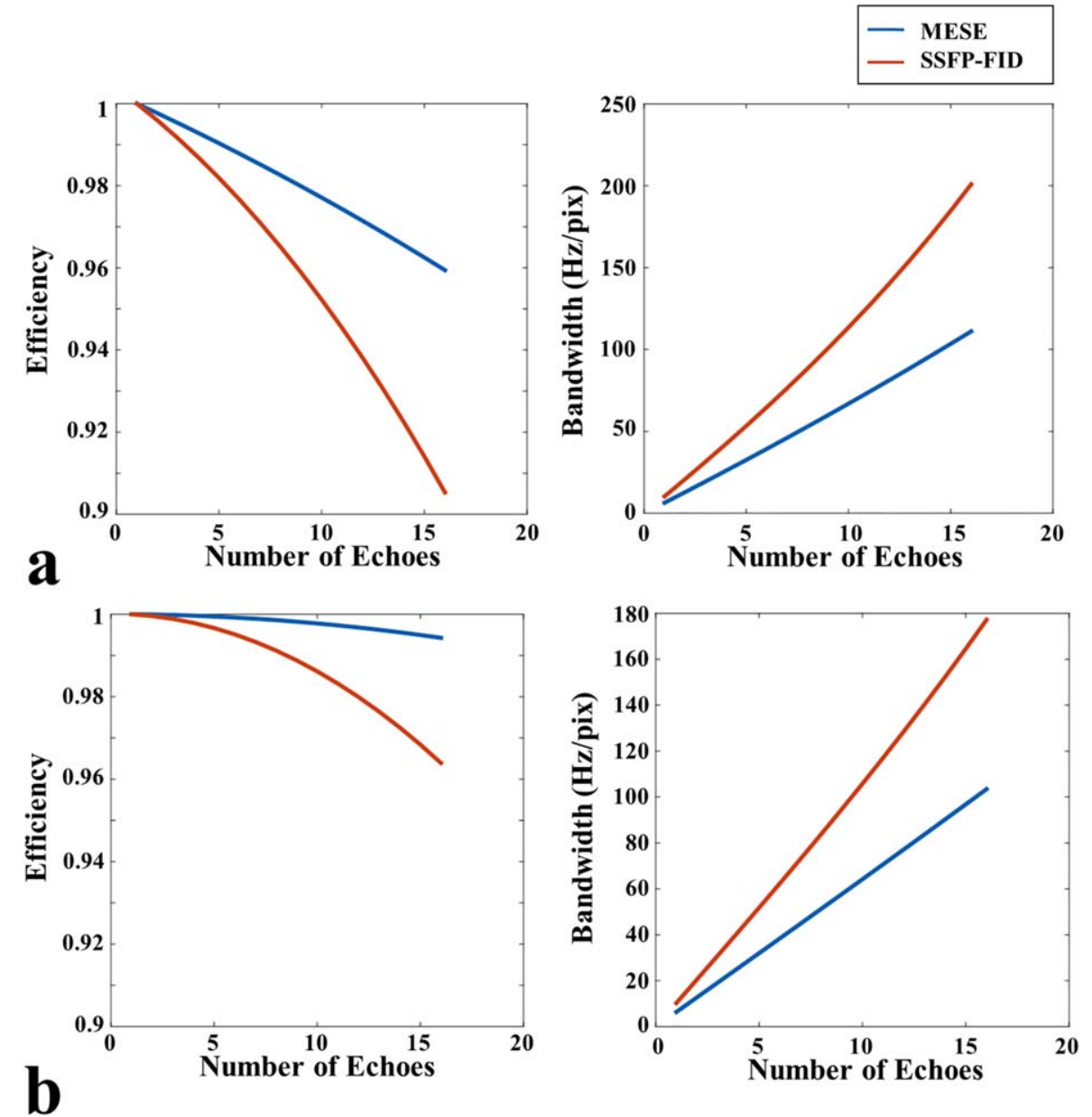

strategies (28) are not needed (the distortions depend on the ratio between current-induced magnetic field and the readout gradient magnitude). In line with this, our simulations and measurements indicate that the steady-state magnitude response is only insignificantly affected by weak $\Delta \mathrm{B}_{\mathrm{z}, \mathrm{c}}$, and there was no observable distortions in the magnitude images.

For MESE, the highest efficiencies were reached at echo spacings of $\mathrm{T}_{\mathrm{ES}}=[80-100] \mathrm{ms}$ when using two to three echoes and a rather long dead time of $\mathrm{T}_{\mathrm{D}}=1.5 \mathrm{~s}$. This is interesting, because it highlights the importance of allowing for sufficient $T_{1}$ recovery to boost signal intensity and by that also the SNR and efficiency of the $\Delta \mathrm{B}_{\mathrm{z}, \mathrm{c}}$ images. It further opens up the possibility to use the dead time to acquire additional slices without decreasing efficiency. The parameters giving highest efficiency depend on the chosen RF pulse width, crusher gradients duration, and the efficiency of refocusing pulses. In particular, increasing the efficiency of the refocusing pulses above the $86 \%$ achieved in our phantom experiments may result in higher efficiencies with shorter $\mathrm{T}_{\mathrm{ES}}$ and more echoes. This might be feasible for some human applications attributed to a better RF field homogeneity, for example, in the upper part of the brain. It is important to note that efficiency improvements by the combination of multiple echoes depend on a proper design of the crusher gradients to allow a linear phase accumulation over echoes. The systematic arrangement of crusher gradients in this study (doubling up gradient area or changing direction) guarantees elimination of unwanted echoes, at a cost of large crusher widths. This may cause small signal loss attributed to diffusion weighting, eddy currents, or concomitant magnetic fields, which are not quantified in this study. Alternative methods, such as random crusher variation, do not guarantee the complete elimination of unwanted echoes.

Two different SSFP-FID variants were considered, with the current being injected until $\mathrm{T}_{\mathrm{E}}$ (as originally investigated in a previous work (19)) and within the entire $T_{R}$ period, respectively. Because the later variant exhibited increased phase sensitivity, it was considered further in the efficiency analyses. The maximal efficiency occurred for echo times of $\mathrm{T}_{\mathrm{E}}=[60-90] \mathrm{ms}$, repetition times of $\mathrm{T}_{\mathrm{R}}=[120-180] \mathrm{ms}$, and tip angles of $\alpha=30^{\circ}$.

Our main focus was on determining optimal parameter ranges. For this, relative, rather than absolute, efficiency values were sufficient, as obtained in the simulations. However, we also directly compared the measured absolute efficiencies between optimized MESE and SSFP-FID sequences. The results demonstrate that SSFP-FID has 3 times higher efficiency compared to MESE. The SNR of the reconstructed $\Delta \mathrm{B}_{\mathrm{z}, \mathrm{c}}$ images are in a similar range, but the total scan time is substantially shorter for SSFP-FID. 


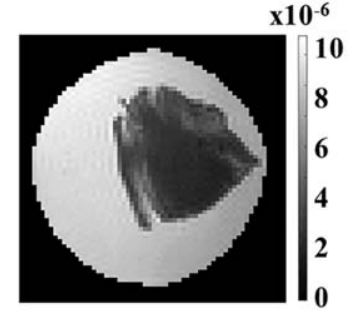

a

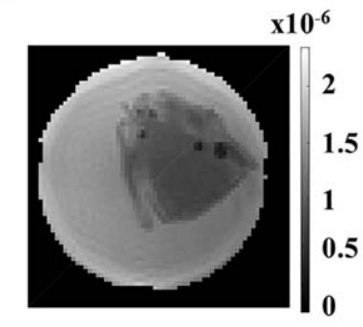

d

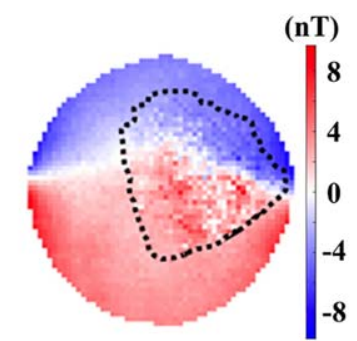

b

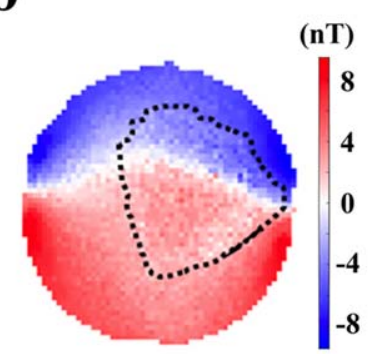

$\mathbf{e}$

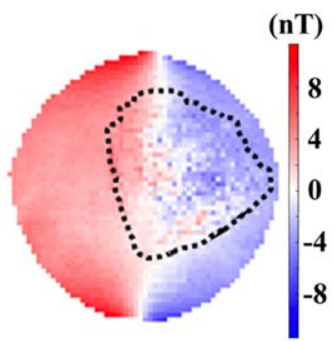

c

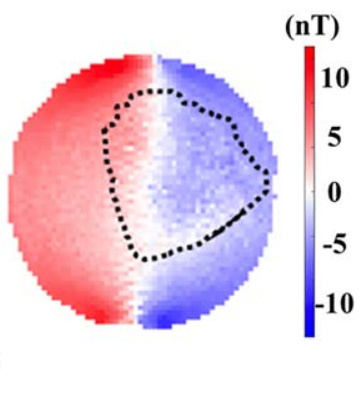

FIG. 10. Results for Phantom 2. (a) Combined magnitude image for MESE. (b) Combined $\Delta \mathrm{B}_{\mathrm{z}, \mathrm{c}}$ images for MESE (horizontal current injection). (c) Combined $\Delta \mathrm{B}_{\mathrm{z}, \mathrm{c}}$ images for MESE (vertical current injection). (d) Averaged magnitude image for SSFP-FID $\mathrm{FCI}_{\mathrm{F}}$ (e) Reconstructed $\Delta \mathrm{B}_{\mathrm{z}, \mathrm{c}}$ image for SSFP-FID $\mathrm{FCl}_{\text {(n) }}$ (horizontal current injection). (f) Reconstructed $\Delta \mathrm{B}_{\mathrm{z}, \mathrm{c}}$ image for SSFP-FID $\mathrm{FCl}_{\mathrm{Fl}}$ (vertical current injection). The parameters for MESE were $\mathrm{FOV}=192 \times 192 \mathrm{~mm}^{2}$, image matrix $=128 \times 128, \Delta \mathrm{z}=3 \mathrm{~mm}, \mathrm{~N}_{\text {echo }}=3, \mathrm{BW}=100 \mathrm{~Hz} / \mathrm{pixel}$, $\mathrm{N}_{\mathrm{avg}}=1, \mathrm{~T}_{\mathrm{ES}}=80 \mathrm{~ms}$, and $\mathrm{T}_{\mathrm{D}}=510 \mathrm{~ms}$. The parameters for $S S F P-F I D_{F C l}$ were $F O V=192 \times 192 \mathrm{~mm}^{2}$, image matrix $=128 \times 128$, $\Delta z=3 \mathrm{~mm}, \mathrm{BW}=100 \mathrm{~Hz} /$ pixel, $\mathrm{N}_{\text {avg }}=16 \times 2, \alpha=20^{\circ}, \mathrm{T}_{\mathrm{E}}=15 \mathrm{~ms}$, and $\mathrm{T}_{\mathrm{R}}=30 \mathrm{~ms}$. The injected current magnitude was $\mathrm{I}_{\mathrm{C}}=1 \mathrm{~mA}$.

On the other hand, MESE has a better image quality, is robust to $B_{0}$ inhomogeneities, and is better suited for multi-slice experiments. Attributed to the robustness to $\mathrm{B}_{0}$ inhomogeneities, MESE might perform better than SSFP-FID in regions with very short $\mathrm{T}_{2}^{*}$ (Supporting Fig. S4e,f).

Our results show that the efficiency is maximized for rather long echo spacings (for MESE) and echo times (for SSFP-FID), respectively. This also implies low readout bandwidths to optimize the SNR, resulting in considerable image distortions attributed to $B_{0}$ inhomogeneities. We suggest that this problem can be ameliorated without substantial decrease in efficiency when multiple gradient echoes are acquired at a higher BW during each readout period and are subsequently added (17). This strategy should result in a good image quality for MESE, for which the signal evolution is robust to $B_{0}$ inhomogeneities. SSFP-FID sequences are generally more susceptible to local $\mathrm{B}_{0}$ inhomogeneities, so that the $\mathrm{T}_{\mathrm{R}}$ (and thus also $\mathrm{T}_{\mathrm{E}}$ ), which can be achieved in practice, might be lower than the one required to maximize efficiency.

To summarize, in our phantom study, the optimized MESE and SSFP-FID sequences allowed for a reliable measurement of the magnetic field created by currents of $1 \mathrm{~mA}$ or below. This is promising for the exploration of these sequences for in-vivo brain imaging applications. Future sequence optimizations might use multi-gradientecho readouts to combine high efficiencies with good image quality. Also, other sequences might further improve the efficiency, for example, balanced SSFP MREIT attributed to its very high phase sensitivity (29). Further studies are needed to evaluate the image quality in-vivo, which also depends on the sensitivity of the sequence, for example, to physiological noise and subject motion.

\section{REFERENCES}

1. Mikac U, Demsar F, Beravs K, Sersa I. Magnetic resonance imaging of alternating electric currents. Magn Reson Imaging 2001;19:845-856.

2. Eyüboğlu BM. Magnetic resonance current density imaging. In Wiley Encyclopedia of Biomedical Engineering, Vol. 4, Metin Akay, ed. Hoboken, NJ, USA: Wiley-Interscience; 2006:2147-2153.

3. Eyüboğlu BM. Magnetic resonance electrical impedance tomography. In Wiley Encyclopedia of Biomedical Engineering, Vol. 4, Metin Akay, ed. Hoboken, NJ, USA: Wiley-Interscience; 2006:2154-2162.

4. Seo JK, Woo EJ. Magnetic resonance electrical impedance tomography. Soc Ind Appl Math 2011;53:40-68.

5. Scott GC, Joy ML, Armstrong RL, Henkelman RM. Measurement of nonuniform current density by magnetic resonance. IEEE Trans Med Imaging 1991;10:362-374.

6. Woo EJ, Lee SY, Mun CW. Impedance tomography using internal current density distribution measured by nuclear magnetic resonance. SPIE 1994;2299:377-385.

7. Seo JK, Woo EJ. Electrical tissue property imaging at low frequency using MREIT. IEEE Trans Biomed Eng 2014;61:1390-1399.

8. Fear EC, Hagness SC, Meaney PM, Okoniewski M, Stuchly MA. Enhancing breast tumor detection with near-field imaging. IEEE Microw Mag 2002;3:48-56.

9. Mosher JC, Leahy RM, Lewis PS. EEG and MEG: forward solutions for inverse methods. IEEE Trans Biomed Eng 1999;46:245-259.

10. Opitz A, Paulus W, Will S, Antunes A, Thielscher A. Determinants of the electric field during transcranial direct current stimulation. Neuroimage 2015;109:140-150.

11. Thielscher A, Opitz A, Windhoff M. Impact of the gyral geometry on the electric field induced by transcranial magnetic stimulation. Neuroimage 2011;54:234-243.

12. Göksu C, Sadighi M, Eroğlu HH, Eyüboğlu M. Realization of magnetic resonance current density imaging at 3 Tesla. In: Annual International Conference of the IEEE Engineering in Medicine and Biology Society, EMBC, 2014. pp. 1115-1118.

13. Utz KS, Dimova V, Oppenländer K, Kerkhoff G. Electrified minds: transcranial direct current stimulation (tDCS) and Galvanic Vestibular 
Stimulation (GVS) as methods of non-invasive brain stimulation in neuropsychology - a review of current data and future implications. Neuropsychologia 2010;48:2789-2810.

14. Minhas AS, Jeong WC, Kim YT, Han Y, Kim HJ, Woo EJ. Experimental performance evaluation of multi-echo ICNE pulse sequence in magnetic resonance electrical impedance tomography. Magn Reson Med 2011;66:957-965.

15. Sadleir R, Grant S, Zhang SU, Oh SH, Lee B Il, Woo EJ. High field MREIT: setup and tissue phantom imaging at $11 \mathrm{~T}$. Physiol Meas 2006;27:S261-S270.

16. Hamamura MJ, Muftuler LT. Fast imaging for magnetic resonance electrical impedance tomography. Magn Reson Imaging 2008;26:739745 .

17. Nam HS, Kwon OI. Optimization of multiply acquired magnetic flux density $\mathrm{B}(\mathrm{z})$ using ICNE-Multiecho train in MREIT. Phys Med Biol 2010;55:2743-2759.

18. Birgül Ö, Eyüboğlu BM, Ider YZ. Magnetic resonance-conductivity imaging using 0.15 Tesla MRI scanner. In: 2001 Proceedings of the 23rd Annual EMBS International Conference, 2001. pp. 3384-3387.

19. Lee H, Jeong WC, Kim HJ, Woo EJ, Park J. Alternating steady state free precession for estimation of current-induced magnetic flux density: a feasibility study. Magn Reson Med 2016;75:2009-2019.

20. Pohmann R, von Kienlin M, Haase A. Theoretical evaluation and comparison of fast chemical shift imaging methods. J Magn Reson 1997;129:145-160

21. Scott GC, Joy MLG, Armstrong RL, Henkelman RM. Sensitivity of magnetic-resonance current-density imaging. J Magn Reson 1992;97: 235-254.

22. Sadleir R, Grant S, Zhang SU, et al. Noise analysis in magnetic resonance electrical impedance tomography at 3 and $11 \mathrm{~T}$ field strengths. Physiol Meas 2005;26:875-884.

23. Scheffler K, Maderwald S, Ladd ME, Bieri O. Oscillating steady states. Magn Reson Med 2006;55:598-603.

24. Wansapura JP, Holland SK, Dunn RS, Ball WS. NMR relaxation times in the human brain at 3.0 Tesla. J Magn Reson Imaging 1999;9:531538.

25. Jaynes ET. Matrix treatment of nuclear induction. Phys Rev 1955;98: 1099-1105

26. Walsh DO, Gmitro AF, Marcellin MW. Adaptive reconstruction of phased array MR imagery. Magn. Reson. Med. 2000;43:682-690.

27. Bernstein MA, King KF, Zhou XJ (eds). Handbook of MRI Pulse Sequences. Oxford, UK: Elsevier Academic; 2004.

28. Park C, Lee B Il, Kwon O, Woo EJ. Measurement of induced magnetic flux density using injection current nonlinear encoding (ICNE) in MREIT. Physiol Meas 2007;28:117-127.
29. Bieri O, Maderwald S, Ladd ME, Scheffler K. Balanced alternating steady-state elastography. Magn Reson Med 2006;55:233-241.

30. Scheffler K. A pictorial description of steady-states in rapid magnetic resonance imaging. Concepts Magn Reson 1999;11:291-304.

31. Tofts PS. QA: quality assurance, accuracy, precision and phantoms. Quant MRI Brain 2003:55-81.

32. Insko E, Bolinger L. Mapping of the radiofrequency field. J Magn Reson 1993;103:82-85.

\section{SUPPORTING INFORMATION}

Additional supporting information can be found in the online version of this article.

Fig. S1. MESE results. (a) Simulated and (b) measured dependence of $\mathrm{SNR}_{\triangle \mathrm{BZC}}$ on the acquired number of echoes and on $\mathrm{T}_{\mathrm{ES}}$. Results are normalized relative to their maximal values. The measurement and simulation parameters are $\mathrm{FOV}=300 \times 300 \mathrm{~mm}^{2}$, image matrix $=256 \times 256$, $\Delta \mathrm{z}=5 \mathrm{~mm}, \mathrm{~N}_{\text {slice }}=1, \mathrm{~N}_{\text {avg }}=1, \mathrm{~N}_{\text {echo }}=[1-8], \mathrm{T}_{\mathrm{ES}}=[20-160] \mathrm{ms}, \mathrm{T}_{\mathrm{D}}=510$ $\mathrm{ms}, \mathrm{T}_{1}=1.1 \mathrm{~s}, \mathrm{~T}_{2}=100 \mathrm{~ms}, \mathrm{~T}_{2}^{*}=50 \mathrm{~ms}$, and $\mathrm{I}_{\mathrm{C}}=0.5 \mathrm{~mA}$. In both measurements and simulations, the lowest possible BW is selected to maximize the SNR of the MR magnitude image.

Fig. S2. (a) Simulated dependency of the magnitude of the steady-state transverse magnetization on $\Delta \mathrm{B}_{z, c}$ for SSFP-FID. (b) Measured dependencies of the magnitude of the transverse magnetization on the injected current strength for SSFP-FID magnitude when increasing $T_{E}$ is usually expected for SSFP-FID sequences attributed to $\mathrm{T}_{2}^{*}$ decay. However, this is only the case when holding the BW fixed. Here, the experiments were performed for the lowest possible BW (with $T_{E}$ adjusted to $T_{R} / 2$ ), which caused increases in the signal magnitude up to $T_{E}=[60-80] \mathrm{ms}$. (c) Measured dependencies of the magnitude of the

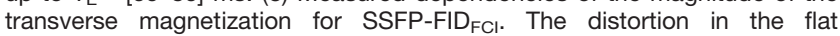
response at $T_{R}=10 \mathrm{~ms}$ and $\mathrm{I}_{C}=6 \mathrm{~mA}$ may have been caused by hardware imperfection. The results were obtained for $\mathrm{T}_{\mathrm{R}}=[10,30,50] \mathrm{ms}$ and $\mathrm{I}_{\mathrm{C}}=[-$ 10 to 10$] \mathrm{mA}$.

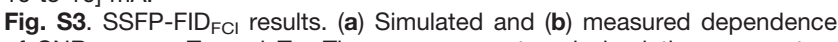
of $\mathrm{SNR}_{\triangle \mathrm{Bz}, \mathrm{C}}$ on $\mathrm{T}_{E}$ and $\mathrm{T}_{\mathrm{R}}$. The measurement and simulation parameters are $\mathrm{N}_{\text {avg }}=2 \times 2$ (two separate averages for each steady state), $\mathrm{T}_{\mathrm{E}}=[10$ 140] $\mathrm{ms}, \mathrm{T}_{\mathrm{R}}=[20-260] \mathrm{ms}, \mathrm{T}_{1}=1.1$ seconds, $\mathrm{T}_{2}=100 \mathrm{~ms}, \mathrm{~T}_{2}^{*}=50 \mathrm{~ms}$, voxel size $=1.5 \times 1.5 \times 3 \mathrm{~mm}^{3}$, image matrix $=256 \times 256$, and $\mathrm{I}_{\mathrm{C}}=1 \mathrm{~mA}$. In both measurements and simulations, the readout is symmetrical around $T_{E}$ and the lowest possible BW is selected to maximize SNR of the MR magnitude image. For impossible combinations of $T_{E}$ and $T_{R}$ (i.e., $T_{E}>T_{R}$ ), the SNR values were set to 0 .

Fig. S4. Dependence of the maximal efficiency of MESE (a,c,e) and SSFP$\mathrm{FID}_{\mathrm{FCl}}(\mathbf{b}, \mathbf{d}, \mathbf{f})$ on the relaxation parameters $\mathrm{T}_{1}, \mathrm{~T}_{2}$, and $\mathrm{T}_{2}^{*}$. The simulations were performed by varying one of the relaxation parameters while keeping the other two fixed and close to the parameters of brain tissue $\left(T_{1}=1.1\right.$ seconds, $T_{2}=100 \mathrm{~ms}$, and $T_{2}^{*}=50 \mathrm{~ms}$ ). The simulations are normalized to their maxima. 